\title{
OPEN New species and records of Trichoderma isolated as mycoparasites and endophytes from cultivated and wild coffee in Africa
}

\author{
María del Carmen H. Rodríguez ${ }^{1}$, Harry C. Evans ${ }^{1,2 \bowtie}$, Lucas M. de Abreu ${ }^{1}$, \\ Davi M. de Macedo ${ }^{1}$, Miraine K. Ndacnou ${ }^{1,3}$, Kifle B. Bekele ${ }^{4,5}$ \& Robert W. Barreto ${ }^{1 凶}$
}

A survey for species of the genus Trichoderma occurring as endophytes of Coffea, and as mycoparasites of coffee rusts (Hemileia), was undertaken in Africa; concentrating on Cameroon and Ethiopia. Ninety-four isolates of Trichoderma were obtained during this study: 76 as endophytes of healthy leaves, stems and berries and, 18 directly from colonized rust pustules. A phylogenetic analysis of all isolates used a combination of three genes: translation elongation factor-1 $\alpha$ (tef1), rpb2 and cal for selected isolates. GCPSR criteria were used for the recognition of species; supported by morphological and cultural characters. The results reveal a previously unrecorded diversity of Trichoderma species endophytic in both wild and cultivated Coffea, and mycoparasitic on Hemileia rusts. Sixteen species were delimited, including four novel taxa which are described herein: $T$. botryosum, $T$. caeruloviride, T. lentissimum and T. pseudopyramidale. Two of these new species, T. botryosum and $T$. pseudopyramidale, constituted over $60 \%$ of the total isolations, predominantly from wild C. arabica in Ethiopian cloud forest. In sharp contrast, not a single isolate of Trichoderma was obtained using the same isolation protocol during a survey of coffee in four Brazilian states, suggesting the existence of a 'Trichoderma void' in the endophyte mycobiota of coffee outside of Africa. The potential use of these African Trichoderma isolates in classical biological control, either as endophytic bodyguards-to protect coffee plants from Hemileia vastatrix, the fungus causing coffee leaf rust (CLR)-or to reduce its impact through mycoparasitism, is discussed, with reference to the on-going CLR crisis in Central America.

Species of the ascomycete genus Trichoderma (Hypocreales: Hypocreaceae) are widely distributed in different environments and have a variety of biological activities ${ }^{1}$. In the last two decades various studies have investigated the diversity and taxonomy of Trichoderma and numerous novel species have emerged using DNA sequence data $^{2-5}$. However, despite the various surveys aimed at covering the diversity of this genus, such studies have been concentrated mostly in Asia, Europe and the Americas ${ }^{6-13}$. In contrast, until now, Africa has been poorly covered in terms of assessing the diversity of Trichoderma, with the exception of some studies involving specific regions or ecological niches, such as soil in South Africa ${ }^{14}$. In the case of Trichoderma occurring as endophytes in Coffea, there is a single study covering species isolated from the rhizosphere of C. arabica in Ethiopia ${ }^{15}$.

Fungi belonging to the genus Trichoderma have a recognized role as decomposers ${ }^{16,17}$ and for a long time they were considered to be soil saprotrophs of little practical relevance ${ }^{18,19}$. Currently, it is widely accepted that such a generalization was erroneous and many species of Trichoderma are now recognized as mycoparasites, as well as endophytes of woody plants ${ }^{18,20-24}$. The endophytic interaction between Trichoderma and their host-plants is intimate and may be complex, involving many steps at each level from direct contact to internal colonization of

${ }^{1}$ Departamento de Fitopatologia, Universidade Federal de Viçosa, Viçosa, MG 36570-900, Brazil. ${ }^{2}$ CAB International, Bakeham Lane, Egham, Surrey TW20 9TY, UK. ${ }^{3}$ IRAD-Institut de Recheche Agricole pour le Developpement, BP 2067 Yaoundé, Cameroon. ${ }^{4}$ Department of Horticulture and Plant Science, College of Agriculture and Veterinary Medicine, Jimma University, P.O. Box 397, Jimma, Ethiopia. ${ }^{5}$ Ethiopian Institute of Agriculture Research, P.O. Box 192, Jimma, Ethiopia.『email: h.evans@cabi.org; rbarreto@ufv.br 
tissues ${ }^{19}$. Endophytic Trichoderma may behave as innocuous commensals or as true symbionts; stimulating the plant's defence system in various ways: inducing host resistance to plant pests; promoting tolerance to abiotic stresses; increasing plant growth and photosynthetic capability; and, contributing towards the solubilization of nutrients for the host plant's benefit ${ }^{25-33}$.

Studies on Trichoderma as endophytes in perennial crop plants, particularly in their original wild to semi-wild situations, have revealed a considerable diversity of species-including a number of novel taxa-especially when compared with the same crops in cultivation. Notable examples are cacao, Theobroma cacao $0^{20,34-38}$ and rubber, Hevea brasiliensis ${ }^{8,39-41}$ in their native Amazonian ranges.

Members of Trichoderma compete naturally in the wild with other groups of fungi to occupy niches and obtain nutrients and are capable of producing a range of secondary metabolites, including antibiotics and mycotoxins $s^{18,42,43}$. Another characteristic of Trichoderma is the mycoparasitic ability of certain species which has led them to be considered as potential tools for the control of plant pathogenic fungi ${ }^{21}$. There are several practical examples of the commercial application of mycoparasitic Trichoderma: notably, that of T. stromaticum for control of Moniliophthora perniciosa - the causal agent of witches' broom disease of cacao-the most important disease of the crop in the Neotropics. This mycoparasite colonizes the necrotic brooms of diseased plants, as well as the agaric fruit bodies of the fungus, decreasing inoculum production ${ }^{44}$, and it has also been reported to be a common endophyte in healthy cacao trees ${ }^{45}$. A product based on T. stromaticum (Tricovab) has been distributed to farmers in southern Bahia (Brazil) for a number of years ${ }^{5,46}$, and now forms part of an integrated management strategy $y^{47}$.

Trichoderma species, such as T. harzianum, can colonize and degrade resistant structures (sclerotia) of other plant pathogenic fungi ${ }^{48,49}$, and have been mass-produced and used as commercial bio-fungicides ${ }^{5,50}$. Although the known diversity of Trichoderma is already high, with more than 200 species names recognized, based on molecular phylogeny ${ }^{51,52}$, most research on mycoparasitism has been undertaken with only a few of these species, including: T. harzianum sensu lato, T. atroviride, T. virens, T. asperellum and T. asperelloides ${ }^{49}$, whilst mycoparasitism of rust fungi by Trichoderma has been little studied. The potential of Trichoderma as a tool for the management of plant diseases is now widely recognized, although this approach has virtually been untapped for many diseases of tropical perennial crops. The main aim of this study was to collect, isolate and identify members of the genus Trichoderma from Coffea species and their associated Hemileia rusts in their centres of origin in Africa, with the long-term objective of assessing their potential as biocontrol agents of coffee leaf rust (CLR) caused by Hemileia vastatrix an increasing constraint to coffee production in the Americas ${ }^{53}$.

\section{Results}

Phylogenetic analyses and GCPRS. A total of 94 Trichoderma isolates were obtained during this survey, 76 as endophytes in Coffea spp. and 18 as mycoparasites on coffee rusts (Table 1). The combined data set indicated that the 94 Trichoderma strains grouped into 16 highly supported monophyletic groups (Figs. 1 and 2). The concatenated trees generated in BI, ML and MP analyses shared a similar topology, providing high support to the final trees. Phylogenetic trees and DNA sequence alignment data are available from TreeBase (study S27041).

By following the identification manual for Trichoderm $a^{5}$, five clades were identified amongst our Trichoderma isolates, namely clades: Viride, Virens, Strictipile, Longibrachiatum and Harzianum. Five isolates were grouped into three known species belonging to the clade Harzianum: T. breve ${ }^{12}$, T. guizhouense ${ }^{55}$ and T. aggressivum ${ }^{56}$; one isolate was identified as T. virens in the clade Virens ${ }^{57}$, and three as T. spirale in the clade Strictipile ${ }^{58}$ (Fig. 1). Three isolates were grouped in T. parareese $i^{59}$, belonging to the Longibrachiatum clade and an additional isolate, obtained from Brazil (as a mycoparasite of CLR pustules), also fell within this clade, and was identified as T. andinense $^{2}$ (Fig. 2). Twenty-one isolates were grouped into five species of the Viride clade: T. koningiopsis ${ }^{60}, T$. petersenii $^{60}$, T. theobromicola ${ }^{22}$, T. hamatum ${ }^{61}$ and T. atroviride ${ }^{62}$ (Fig. 2). Fifty-nine isolates grouped in three phylogenetic species belonging to the clade Harzianum and one isolate belonging to the Viride clade did not correspond to any known species and were considered as new taxa, described in this work as: T. lentissimum sp. nov., T. caeruloviride sp. nov.., T. botryosum sp. nov. and T. pseudopyramidale sp. nov. (Figs. 1 and 2). In order to clarify the phylogenetic relationship between T. pseudopyramidale sp. nov. and T. pyramidale, an analysis was performed with the addition of calmodulin sequences. The results of the analysis supported the distinction between T. pyramidale and the new species (Fig. 3). The isolates identified in this study as T. pseudopyramidale were positioned as paraphyletic with T. pyramidale reference isolates, in the tef tree (Fig. 4 ) and in the $r p b 2$ tree (Fig. 5), the sequence of the single available reference isolate of T. pyramidale (S73) was distant from the $T$. pseudopyramidale clade.

The single tef and rpb2 trees for the Longibrachiatum and Viride clades were highly congruent (Figs. 6 and 7) with the topology of the concatenated tree (Fig. 2); the same was observed with the individual trees tef and $r p b 2$ of the clade Harzianum (Figs. 4 and 5) with the topology concatenated (Fig. 1), except for the isolates identified as $T$. breve (indicated with number 1, Fig. 5), when evaluated in the $r p b 2$ tree. The reference isolates of this species were placed in two polyphyletic species and one of the isolates of this study attributed to T. breve were positioned outside the monophyletic groups (they remained as singletons) in this analysis. In the tef tree the clades Stricpile and Virens divided the largest clade (Harzianum) (Fig. 4), however the grouping of the species identified in this study were similar to the concatenated tree (Fig. 1).

Diversity and distribution. Although the collections of plant material were not systematic-and, therefore, there was no purpose in quantifying the frequency of colonization of plants by species of Trichoderma in this study-it was possible to identify patterns of occurrence of taxa, in terms of region/locality, host Coffea species and plant tissue type. For example, it was observed that T. koningiopsis was isolated only from leaves; whilst T. theobromicola, T. guizhouense and T. spirale were isolated exclusively from stems; and T. caeruloviride sp. nov. 


\begin{tabular}{|c|c|c|c|c|c|c|}
\hline \multirow[b]{2}{*}{ Taxon } & \multirow[b]{2}{*}{ Isolate } & \multirow[b]{2}{*}{ Country } & \multirow[b]{2}{*}{ Substrate } & \multicolumn{3}{|c|}{ Genbank accession numbers } \\
\hline & & & & tef & $r p b 2$ & cal \\
\hline T. aggressivum & COAD 2432 & Kenya & Hemileia sp. Mycoparasite & MK044156 & MK044249 & - \\
\hline T. andinense & COAD 2431 & Brazil & Hemileia vastatrix, Mycoparasite & MK044155 & MK044248 & - \\
\hline T. atroviride & COAD 2396 & Kenya & Leaf, Coffea sp. Endophyte & MK044083 & MK044177 & - \\
\hline T. botryosum sp. nov. & COAD 2422 & \begin{tabular}{|l|} 
Ethiopia \\
\end{tabular} & Berry, Coffea arabica Endophyte & MK044119 & MK044212 & - \\
\hline T. botryosum sp. nov. & COAD 2401 & Cameroon & Stem, Coffea canephora Endophyte & MK044088 & MK044181 & - \\
\hline T. botryosum sp. nov. & COAD 2403 & Cameroon & Stem, Coffea arabica Endophyte & MK044090 & MK044183 & - \\
\hline T. botryosum sp. nov. & COAD 2505 & Ethiopia & Stem, Coffea arabica Endophyte & MK044112 & MK044205 & \\
\hline T. botryosum sp. nov. & COAD 2507 & Ethiopia & Berry, Coffea arabica Endophyte & MK044116 & MK044209 & - \\
\hline T. botryosum sp. nov. & COAD 2424 & Ethiopia & Leaf, Coffea arabica Endophyte & MK044121 & MK044214 & - \\
\hline T. botryosum sp. nov. & COAD 2538 & Ethiopia & Leaf, Coffea arabica Endophyte & MK044122 & MK044215 & - \\
\hline T. botryosum sp. nov. & COAD 2511 & Ethiopia & Leaf, Coffea arabica Endophyte & MK044126 & MK044219 & - \\
\hline T. botryosum sp. nov. & COAD 2541 & Ethiopia & Stem, Coffea arabica Endophyte & MK044138 & MK044231 & - \\
\hline T. botryosum sp. nov. & COAD 2542 & Ethiopia & Stem, Coffea arabica Endophyte & MK044139 & MK044232 & - \\
\hline T. botryosum sp. nov. & COAD 2520 & Ethiopia & Stem, Coffea arabica Endophyte & MK044140 & MK044233 & - \\
\hline T. botryosum sp. nov. & COAD 2543 & Ethiopia & Stem, Coffea arabica Endophyte & MK044141 & MK044234 & - \\
\hline T. botryosum sp. nov. & COAD 2521 & Ethiopia & Stem, Coffea arabica Endophyte & MK044142 & MK044235 & - \\
\hline T. botryosum sp. nov. & COAD 2522 & Ethiopia & Stem, Coffea arabica Endophyte & MK044143 & MK044236 & - \\
\hline T. botryosum sp. nov. & COAD 2423 & Ethiopia & Stem, Coffea arabica Endophyte & MK044144 & MK044237 & - \\
\hline T. botryosum sp. nov. & COAD 2524 & Ethiopia & stem, Coffea arabica Endophyte & MK044145 & MK044238 & - \\
\hline T. botryosum sp. nov. & COAD 2525 & Ethiopia & Stem, Coffea arabica Endophyte & MK044146 & MK044239 & - \\
\hline T. botryosum sp. nov. & COAD 2526 & Ethiopia & Stem, Coffea arabica Endophyte & MK044147 & MK044240 & - \\
\hline T. botryosum sp. nov. & COAD 2428 & Ethiopia & Berry, Coffea arabica Endophyte & MK044148 & MK044241 & - \\
\hline T. botryosum sp. nov. & COAD 2527 & Ethiopia & Leaf, Coffea arabica Endophyte & MK044149 & MK044242 & - \\
\hline T. botryosum sp. nov. & COAD 2528 & Ethiopia & Leaf, Coffea arabica Endophyte & MK044151 & MK044244 & - \\
\hline T. botryosum sp. nov. & COAD 2430 & Ethiopia & Leaf, Coffea arabica Endophyte & MK044152 & MK044245 & - \\
\hline T. breve & COAD 2402 & Cameroon & Stem, Coffea canephora Endophyte & MK044089 & MK044182 & - \\
\hline T. breve & COAD 2429 & Ethiopia & Berry, Coffea arabica Endophyte & MK044150 & MK044243 & - \\
\hline T. caeruloviride sp. nov. & COAD 2416 & Ethiopia & Berry, Coffea arabica Endophyte & MK044108 & MK044201 & - \\
\hline T. caeruloviride sp. nov. & COAD 2415 & Ethiopia & Berry, Coffea arabica Endophyte & MK044109 & MK044202 & - \\
\hline T. guizhouense & COAD 2397 & Kenya & stem, Coffea sp Endophyte & MK044084 & MK044176 & - \\
\hline T. guizhouense & COAD 2398 & Kenya & Stem, Coffea sp. Endophyte & MK044085 & MK044178 & - \\
\hline T. hamatum & COAD 2417 & Ethiopia & Stem, Coffea arabica Endophyte & MK044110 & MK044203 & - \\
\hline T. hamatum & COAD 2418 & Ethiopia & Stem, Coffea arabica Endophyte & MK044111 & MK044204 & - \\
\hline T. hamatum & COAD 2423 & Ethiopia & Berry, Coffea arabica Endophyte & MK044120 & MK044213 & - \\
\hline T. koningiopsis & COAD 2405 & Cameroon & Leaf, Coffea canephora Endophyte & MK044092 & MK044185 & - \\
\hline T. koningiopsis & COAD 2502 & Cameroon & Leaf, Coffea canephora Endophyte & MK044097 & MK044190 & - \\
\hline T. koningiopsis & COAD 2537 & Cameroon & Leaf, Coffea canephora Endophyte & MK044098 & MK044191 & - \\
\hline T. koningiopsis & COAD 2409 & Cameroon & Stem, Coffea canephora Endophyte & MK044099 & MK044192 & - \\
\hline T. koningiopsis & COAD 2503 & Cameroon & Leaf, Coffea canephora Endophyte & MK044100 & MK044193 & - \\
\hline T. koningiopsis & COAD 2410 & Cameroon & Leaf, Coffea canephora Endophyte & MK044101 & MK044194 & - \\
\hline T. koningiopsis & COAD 2411 & Cameroon & Leaf, Coffea canephora Endophyte & MK044102 & MK044195 & - \\
\hline T. lentissimum sp. nov. & COAD 2399 & Kenya & $\begin{array}{l}\begin{array}{l}\text { Stem, Coffea cf. arabica Endo- } \\
\text { phyte }^{\mathrm{b}}\end{array} \\
\end{array}$ & МК044086 & MK044179 & - \\
\hline T. parareesei & COAD 2485 & Ethiopia & Hemileia sp. Mycoparasite ${ }^{\mathrm{a}}$ & MK044082 & MK044265 & - \\
\hline T. parareesei & COAD 2482 & Ethiopia & Stem, Coffea arabica Endophyte & MK044153 & MK044246 & - \\
\hline T. parareesei & COAD 2483 & Ethiopia & Stem, Coffea arabica Endophyte & MK044154 & MK044247 & - \\
\hline T. petersenii & COAD 2438 & Ethiopia & Hemileia sp. Mycoparasite & MK044168 & MK044261 & - \\
\hline T. pseudopyramidale sp. nov. & COAD 2419 & Ethiopia & Stem, Coffea arabica Endophyte & MK044113 & MK044206 & MK084875 \\
\hline T. pseudopyramidale sp. nov. & COAD 2506 & Ethiopia & Stem, Coffea arabica Endophyte & MK044114 & MK044207 & - \\
\hline T. pseudopyramidale sp. nov. & COAD 2420 & Ethiopia & Stem, Coffea arabica Endophyte & MK044115 & MK044208 & MK084874 \\
\hline T. pseudopyramidale sp. nov. & COAD 2508 & Ethiopia & Leaf, Coffea arabica Endophyte & MK044117 & MK044210 & - \\
\hline T. pseudopyramidale sp. nov. & COAD 2421 & Ethiopia & Leaf, Coffea arabica Endophyte & MK044118 & MK044211 & MK084873 \\
\hline T. pseudopyramidale sp. nov. & COAD 2425 & Ethiopia & Leaf, Coffea arabica Endophyte & MK044123 & MK044216 & MK084871 \\
\hline T. pseudopyramidale sp. nov. & COAD 2509 & Ethiopia & Leaf, Coffea arabica Endophyte & MK044124 & MK044217 & - \\
\hline T. pseudopyramidale sp. nov. & COAD 2510 & Ethiopia & Leaf, Coffea arabica Endophyte & MK044125 & MK044218 & - \\
\hline T. pseudopyramidale sp. nov. & COAD 2540 & Ethiopia & Leaf, Coffea arabica Endophyte & MK044127 & MK044220 & - \\
\hline T. pseudopyramidale sp. nov. & COAD 2512 & Ethiopia & Leaf, Coffea arabica Endophyte & MK044128 & MK044221 & - \\
\hline Continued & & & & & & \\
\hline
\end{tabular}




\begin{tabular}{|c|c|c|c|c|c|c|}
\hline \multirow[b]{2}{*}{ Taxon } & \multirow[b]{2}{*}{ Isolate } & \multirow[b]{2}{*}{ Country } & \multirow[b]{2}{*}{ Substrate } & \multicolumn{3}{|c|}{ Genbank accession numbers } \\
\hline & & & & tef & $r p b 2$ & cal \\
\hline T. pseudopyramidale sp. nov. & COAD 2513 & Ethiopia & Leaf, Coffea arabica Endophyte & MK044129 & MK044222 & - \\
\hline T. pseudopyramidale sp. nov. & COAD 2514 & Ethiopia & Leaf, Coffea arabica Endophyte & MK044130 & MK044223 & - \\
\hline T. pseudopyramidale sp. nov. & COAD 2426 & Ethiopia & Leaf, Coffea arabica Endophyte & MK044131 & MK044224 & MK084870 \\
\hline T. pseudopyramidale sp. nov. & COAD 2515 & Ethiopia & Leaf, Coffea arabica Endophyte & MK044132 & MK044225 & - \\
\hline T. pseudopyramidale sp. nov. & COAD 2516 & Ethiopia & Leaf, Coffea arabica Endophyte & MK044133 & MK044226 & - \\
\hline T. pseudopyramidale sp. nov. & COAD 2517 & Ethiopia & Leaf, Coffea arabica Endophyte & MK044134 & MK044227 & - \\
\hline T. pseudopyramidale sp. nov. & COAD 2518 & Ethiopia & Leaf, Coffea arabica Endophyte & MK044135 & MK044228 & - \\
\hline T. pseudopyramidale sp. nov. & COAD 2427 & Ethiopia & Leaf, Coffea arabica Endophyte & MK044136 & MK044229 & MK084872 \\
\hline T. pseudopyramidale sp. nov. & COAD 2519 & Ethiopia & Leaf, Coffea arabica Endophyte & MK044137 & MK044230 & - \\
\hline T. pseudopyramidale sp. nov. & COAD 2433 & Cameroon & Hemileia sp. Mycoparasite & MK044157 & MK044250 & MK084869 \\
\hline T. pseudopyramidale sp. nov. & COAD 2434 & Ethiopia & Hemileia sp. Mycoparasite $^{\mathrm{a}}$ & MK044158 & MK044251 & MK084868 \\
\hline T. pseudopyramidale sp. nov. & COAD 2529 & Ethiopia & Hemileia sp. Mycoparasite ${ }^{\mathrm{a}}$ & MK044159 & MK044252 & - \\
\hline T. pseudopyramidale sp. nov. & COAD 2435 & Ethiopia & Hemileia sp. Mycoparasite ${ }^{\mathrm{a}}$ & MK044160 & MK044253 & MK084867 \\
\hline T. pseudopyramidale sp. nov. & COAD 2530 & Ethiopia & Hemileia sp. Mycoparasite ${ }^{\mathrm{a}}$ & MK044161 & MK044254 & - \\
\hline T. pseudopyramidale sp. nov. & COAD 2436 & Ethiopia & Hemileia sp. Mycoparasite $^{\mathrm{a}}$ & MK044162 & MK044255 & MK084865 \\
\hline T. pseudopyramidale sp. nov. & COAD 2531 & Ethiopia & Hemileia sp. Mycoparasite ${ }^{\mathrm{a}}$ & MK044163 & MK044256 & - \\
\hline T. pseudopyramidale sp. nov. & COAD 2532 & Ethiopia & Hemileia sp. Mycoparasite ${ }^{\mathrm{a}}$ & MK044164 & MK044257 & - \\
\hline T. pseudopyramidale sp. nov. & COAD 2437 & Ethiopia & Hemileia sp. Mycoparasite ${ }^{\mathrm{a}}$ & MK044165 & MK044258 & MK084866 \\
\hline T. pseudopyramidale sp. nov. & COAD 2533 & Ethiopia & Hemileia sp. Mycoparasite ${ }^{\mathrm{a}}$ & MK044166 & MK044259 & - \\
\hline T. pseudopyramidale sp. nov. & COAD 2534 & Ethiopia & Hemileia sp. Mycoparasite $^{\mathrm{a}}$ & MK044167 & MK044260 & - \\
\hline T. pseudopyramidale sp. nov. & COAD 2535 & Ethiopia & Hemileia sp. Mycoparasite ${ }^{\mathrm{a}}$ & MK044169 & MK044262 & - \\
\hline T. pseudopyramidale sp. nov. & COAD 2536 & Ethiopia & Hemileia sp. Mycoparasite $^{\mathrm{a}}$ & MK044170 & MK044263 & - \\
\hline T. pseudopyramidale sp. nov. & COAD 2439 & Ethiopia & Hemileia sp. Mycoparasite & MK044171 & MK044264 & MK084864 \\
\hline T. pseudopyramidale sp. nov. & COAD 2591 & Ethiopia & Stem, Coffea arabica L. Endophyte & MK044174 & MK044268 & - \\
\hline T. pseudopyramidale sp. nov. & COAD 2592 & Ethiopia & Stem, Coffea arabica L. Endophyte & MK044175 & MK044269 & - \\
\hline T. spirale & COAD 2404 & Cameroon & Stem, Coffea canephora Endophyte & MK044091 & MK044184 & - \\
\hline T. spirale & COAD 2408 & Cameroon & Stem, Coffea canephora Endophyte & MK044096 & MK044189 & - \\
\hline T. spirale & COAD 2413 & Cameroon & Stem, Coffea canephora Endophyte & MK044105 & MK044198 & - \\
\hline T. theobromicola & COAD 2406 & Cameroon & Stem, Coffea canephora Endophyte & MK044093 & MK044186 & - \\
\hline T. theobromicola & COAD 2407 & Cameroon & Stem, Coffea canephora Endophyte & MK044094 & MK044187 & - \\
\hline T. theobromicola & COAD 2501 & Cameroon & Stem, Coffea canephora Endophyte & MK044095 & MK044188 & - \\
\hline T. theobromicola & COAD 2504 & Cameroon & Stem, Coffea canephora Endophyte & MK044103 & MK044196 & - \\
\hline T. theobromicola & COAD 2412 & Cameroon & Stem, Coffea canephora Endophyte & MK044104 & MK044197 & - \\
\hline T. theobromicola & COAD 2440 & Cameroon & Stem, Coffea canephora Endophyte & MK044106 & MK044199 & - \\
\hline T. theobromicola & COAD 2414 & Cameroon & Stem, Coffea canephora Endophyte & MK044107 & MK044200 & - \\
\hline T. theobromicola & COAD 2589 & Cameroon & Stem, Coffea canephora Endophyte & MK044172 & MK044266 & - \\
\hline T. theobromicola & COAD 2590 & Cameroon & Stem, Coffea canephora Endophyte & MK044173 & MK044267 & - \\
\hline T. virens & COAD 2400 & Cameroon & Stem, Coffea brevipes Endophyte & MK044087 & MK044180 & - \\
\hline
\end{tabular}

Table 1. Trichoderma strains obtained in the survey and used in the phylogenetic analyses, with their corresponding geographic origin, host and tissue source. Trichoderma strains isolated during this study.

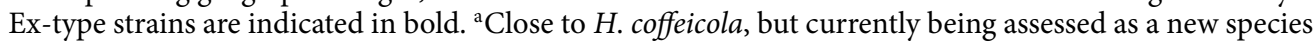
of Hemileia (Authors, unpublished). ${ }^{\mathrm{b}}$ Identified as a wild and geographically-isolated population of Coffea arabica, common in the understorey forest ${ }^{54}$. Kew Herbarium (Herb K) records reflect uncertainty about its true identity; botanical specimens from present survey deposited in Herb K.

was isolated from berries only. The other species were distributed in more than one plant tissue type. The predominant taxon in all plant tissues was T. botryosum sp. nov., but this species was never found as a mycoparasite, whereas T. pseudopyramidale sp. nov. was isolated both as an endophyte and as a mycoparasite-almost exclusively from Ethiopia-being common on Hemileia rust in forest coffee populations. The species T. aggressivum, T. andinensis, T. parareesei and T. petersenii, were isolated only once during the survey, from Kenya, Brazil, and Ethiopia, respectively. In Cameroon, 24 isolates belonging to seven species were found, namely: six species in stem samples (T. botryosum sp. nov., T. koningiopsis, T. breve, T. spirale, T. theobromicola and T. virens), one in leaves (T. koningiopsis), with one isolated only as a mycoparasite (T. pseudopyramidale sp. nov.) (Table 2).

In Ethiopia, 64 isolates belonging to seven species were isolated, namely: 20 isolates of T. botryosum sp. nov. from leaves, stems and berries; 34 isolates of T. pseudopyramidale sp. nov., from leaves and stems, and as mycoparasites; three isolates of $T$. parareesei from stems and one as a mycoparasite; three isolates of T. hamatum from stems and berries; two isolates of T. caeruloviride sp. nov. from berries; one isolate of T. petersenii growing as a 


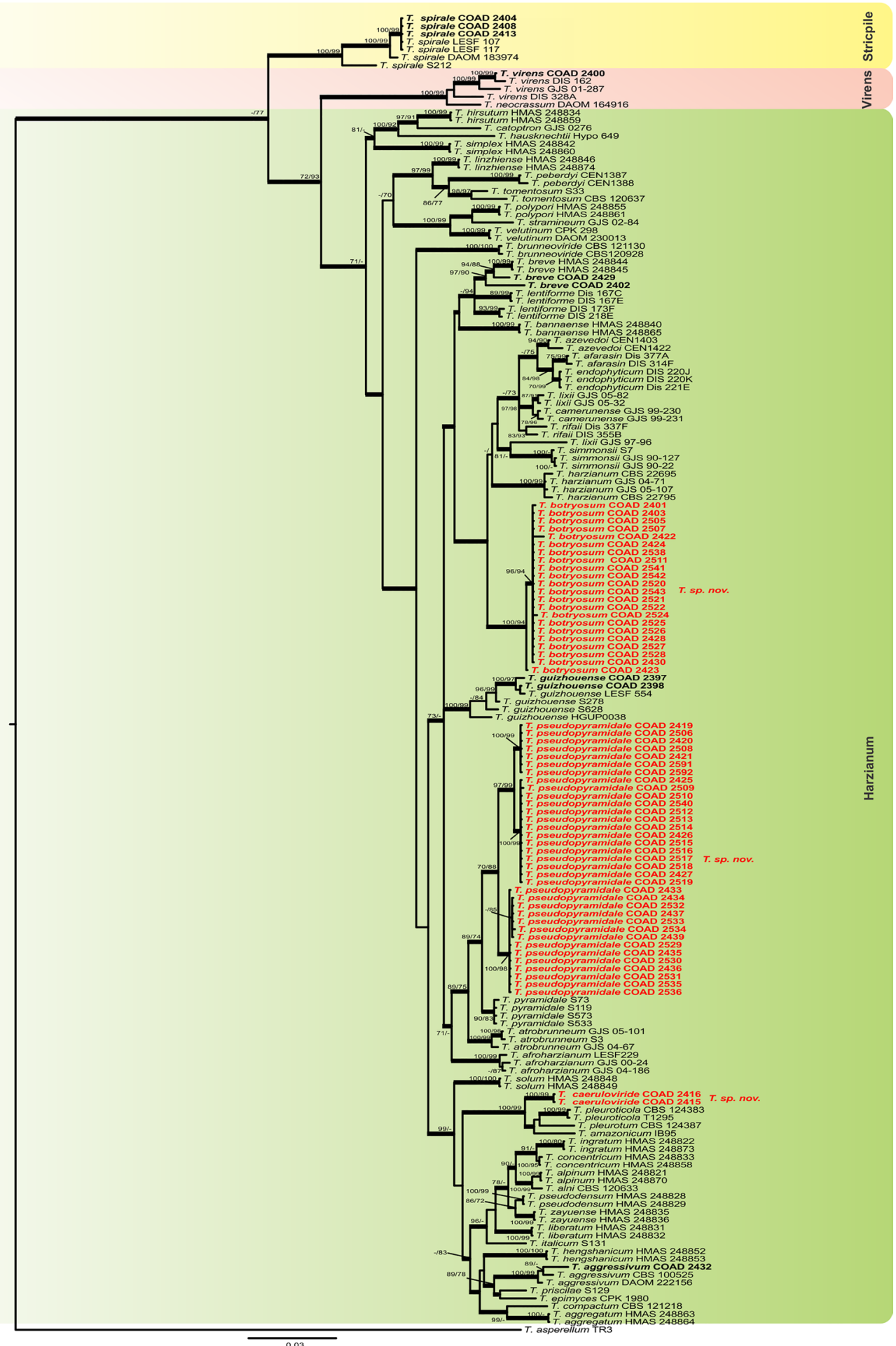

Figure 1. Bayesian phylogenetic tree of clades Harzianum, Strictipile and Virens. The tree was based on a concatenated tef1 and $r p b 2$ sequence dataset. Bootstrap values $(\geq 70 \%)$ of the ML and MP analyses, as well as posterior probability scores $(\geq 0.9)$ from a Bayesian analysis of the same dataset, are indicated at well supported nodes together with thickened branches. The isolates belonging to known species, obtained in this study, are in bold. Isolates of new species, described in this study, are in bold red. The tree was rooted with Trichoderma asperellum (TR3). The phylogenetic tree was edited using Inkscape 1.0 (https://inkscape.org/pt-br/).

mycoparasite and one isolate of T. breve from berries (Table 2). In Kenya, four species were collected, namely: one isolate of T. aggressivum growing as a mycoparasite; one isolate of T. atroviride from leaves; one isolate of T. guizhouense and one of T. lentissimum sp. nov. from stems (Table 2). When the diversity of Trichoderma 


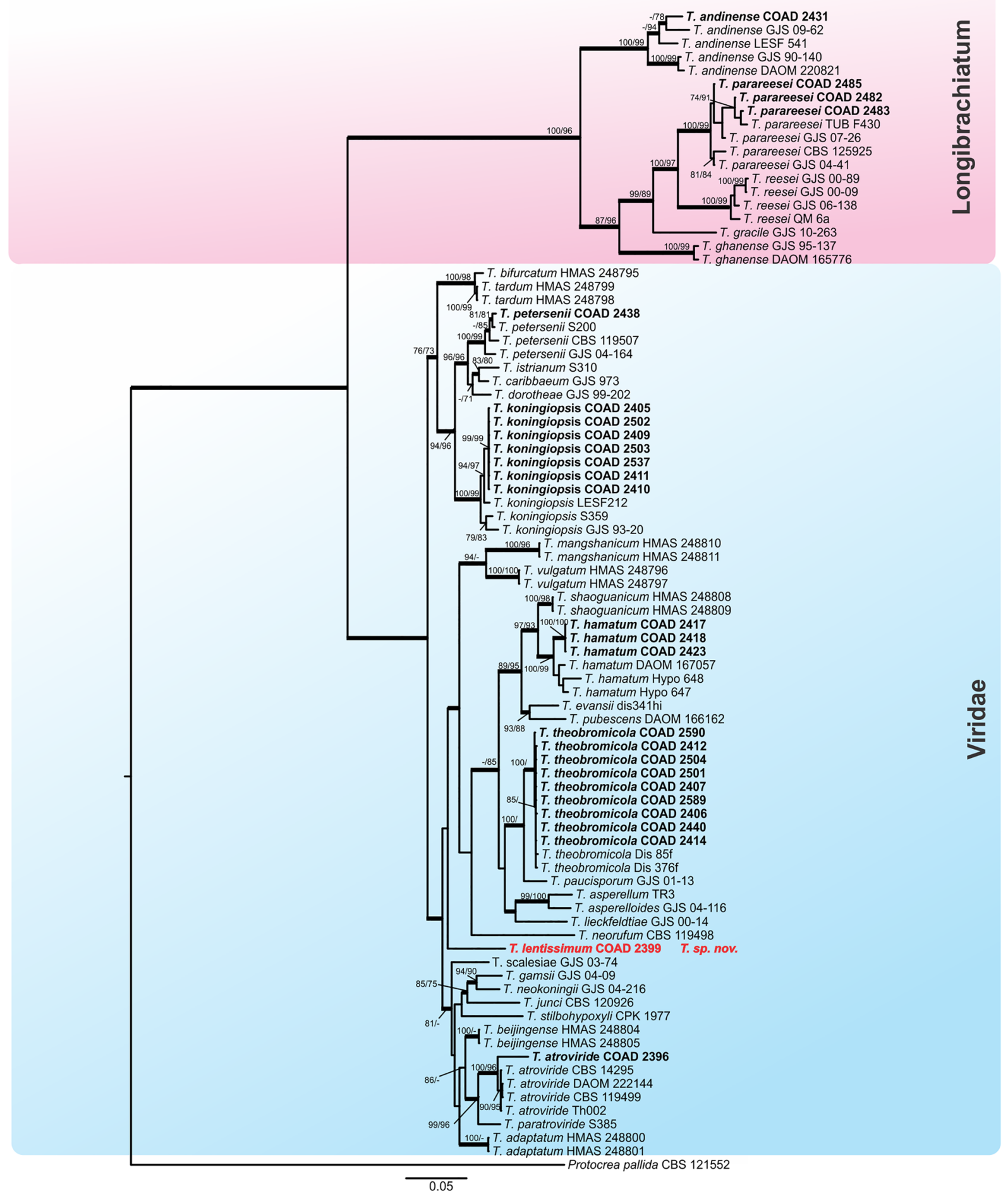

Figure 2. Bayesian phylogenetic tree of clades Longibrachiatum and Viride. The tree was based on a concatenated tef1 and rpb2 sequence dataset. Bootstrap values $(\geq 70 \%)$ of the ML and MP analyses, as well as posterior probability scores $(\geq 0.9)$ from a Bayesian analysis of the same dataset, are indicated at well supported nodes together with thickened branches. The isolates belonging to known species, obtained in this study, are in bold. Isolates of new species, described in this study, are in bold red. The tree was rooted with Protocrea pallida (CBS 121552). The phylogenetic tree was edited using Inkscape 1.0 (https://inkscape.org/pt-br/).

from coffee in West Africa (Cameroon) is compared with that of East Africa (Kenya and Ethiopia), T. breve, T. pseudopyramidale sp. nov. and T. botryosum sp. nov. are the only species which are present both in Ethiopia and Cameroon. The four species found in Kenya were absent from coffee samples in the other countries. Although 


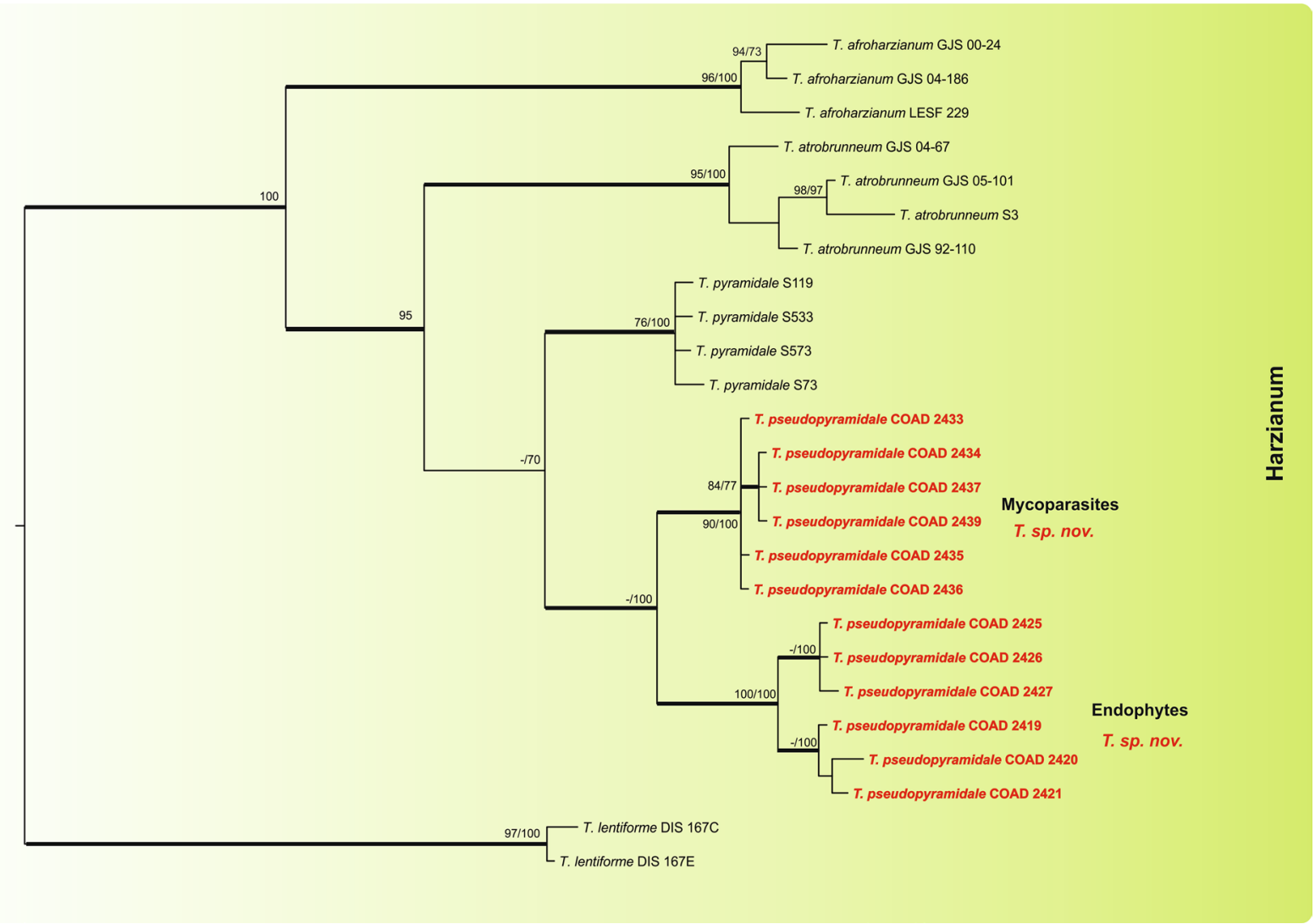

Figure 3. Bayesian phylogenetic tree of T. pyramidale and T. pseudopyramidale sp. nov. The tree was based on a concatenated tef1, rpb2 and cal sequence dataset. Bootstrap values $(\geq 70 \%)$ of the ML and MP analyses, as well as posterior probability scores $(\geq 0.9)$ from a Bayesian analysis of the same dataset, are indicated at well supported nodes together with thickened branches. The isolates belonging to known species, obtained in this study, are in bold. Isolates of new species, described in this study, are in bold red. The tree was rooted with Trichoderma lentiforme (DIS 167C and DIS 167E). The phylogenetic tree was edited using Inkscape 1.0 (https:// inkscape.org/pt-br/).

this suggests strong endemism and isolation of the Trichoderma mycobiota of coffee in Kenya, this should be treated with caution since sampling in Kenya was limited and, thus, this may be an artefact. However, the fact that there was no commonality in species between Kenya and the other countries is intriguing and warrants further investigation. The only Brazilian isolate was identified as T. andinense. The occurrence of T. andinense appeared in an ad hoc isolation during a search for mycoparasites of CLR pustules in Brazil.

The coffee survey in Brazil-aimed at obtaining endophytic Trichoderma from plants growing in semi-wild conditions at eight localities in four states (Table 3)-yielded isolates comprising a range of different genera but just a single isolate was identified as belonging to the genus Trichoderma.

When comparing the number of taxa of Trichoderma present in C. canephora and C. arabica, it was found that both harbour five species but these are distributed differently in the host tissues. The only Trichoderma spp. occurring in both C. arabica and C. canephora were T. breve and T. botryosum sp. nov. In C. arabica, the highest diversity of Trichoderma was found in berries (four species), whereas in C. canephora the highest diversity was found in stems (four species): however, since most of the sampling was focused on C. arabica, it would be premature to reach a firm conclusion. Stems yielded the highest number of isolates from the aerial tissues of Coffea, with 40 (42.6\% of the total), followed by leaves with 29 (30.8\%), and seven isolates (7.4\%) from berries. Mycoparasites, with 18 isolates, formed $19.2 \%$ of the total (Tables 1 and 2).

Taxonomy. Four additions to the genus Trichoderma emerged from the phylogenetic study of the isolates obtained during this survey of Coffea in Africa. Morphological and cultural information proved useful to confirm their separation from closely-related known species of Trichoderma; providing further evidence for their recognition as novel species. Type cultures were deposited in the internationally-recognized culture collection of the Universidade Federal de Viçosa (COAD). The following species were collected and identified, with authority names and publication details as recommended by Bissett et al. ${ }^{52}$.

Trichoderma aggressivum Samuels \& W. Gams-in Samuels et al., Mycologia 94: 167, 2002. MycoBank: MB484638.

Description and illustration, see ${ }^{5,56}$. 


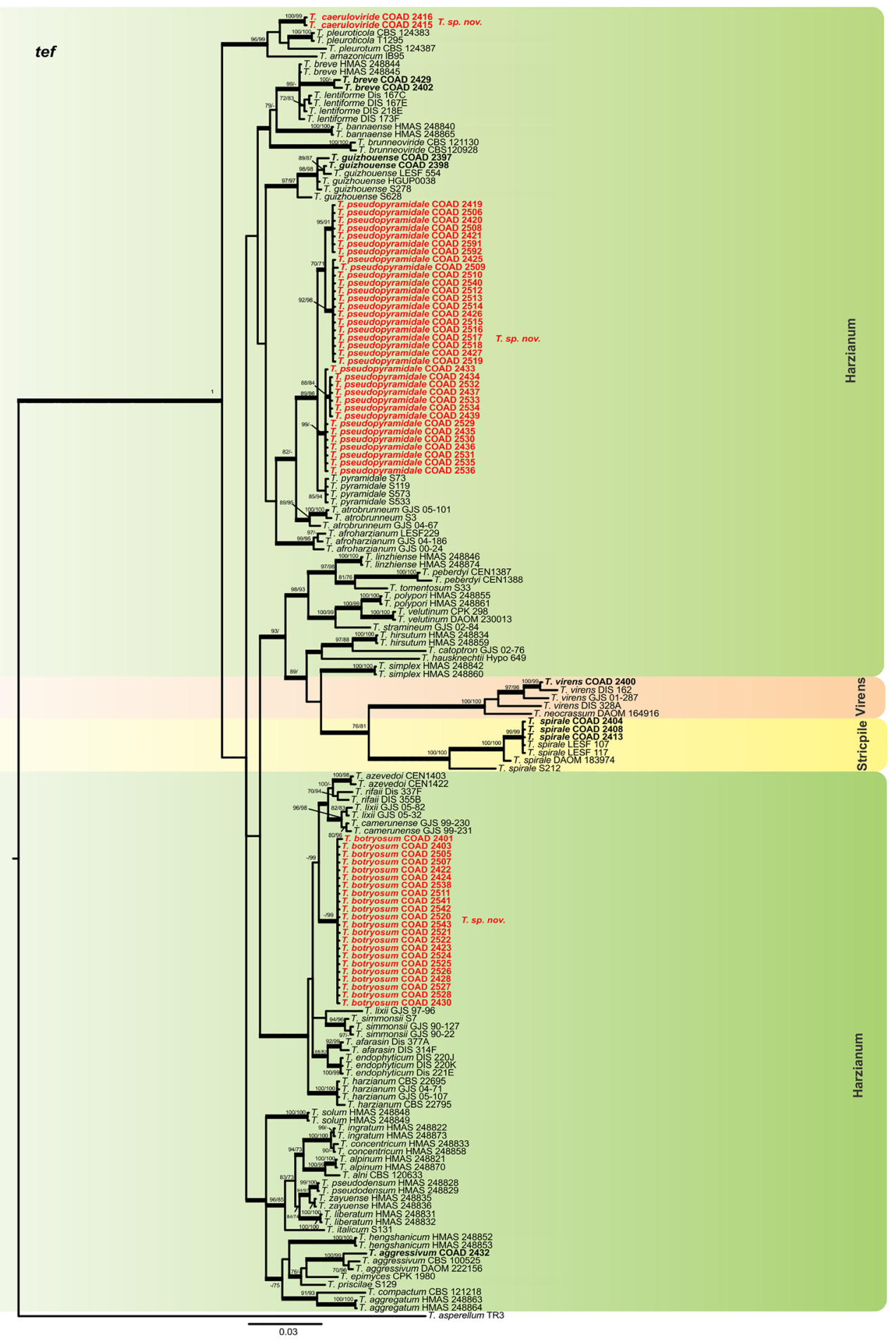

Figure 4. Bayesian phylogenetic tree of clades Harzianum, Strictipile and Virens. The tree was based on tef1 sequence dataset. Bootstrap values $(\geq 70 \%)$ of the ML analyses, as well as posterior probability scores $(\geq 0.9)$ from a Bayesian analysis of the same dataset, are indicated at well supported nodes together with thickened branches. The isolates belonging to known species, obtained in this study are in bold. Isolates of new species, described in this study, are in bold red. The tree was rooted with Trichoderma asperellum (TR3). The phylogenetic tree was edited using Inkscape 1.0 (https://inkscape.org/pt-br/).

Material examined. KENYA: Eastern Province, Marsabit National Park, Lake Paradise, primary forest, alt $1340 \mathrm{~m}$ : isolated as a mycoparasite of Hemileia vastatrix on leaves of Coffea cf. arabica, H.C. Evans \& R.W. Barreto (culture COAD 2432). 


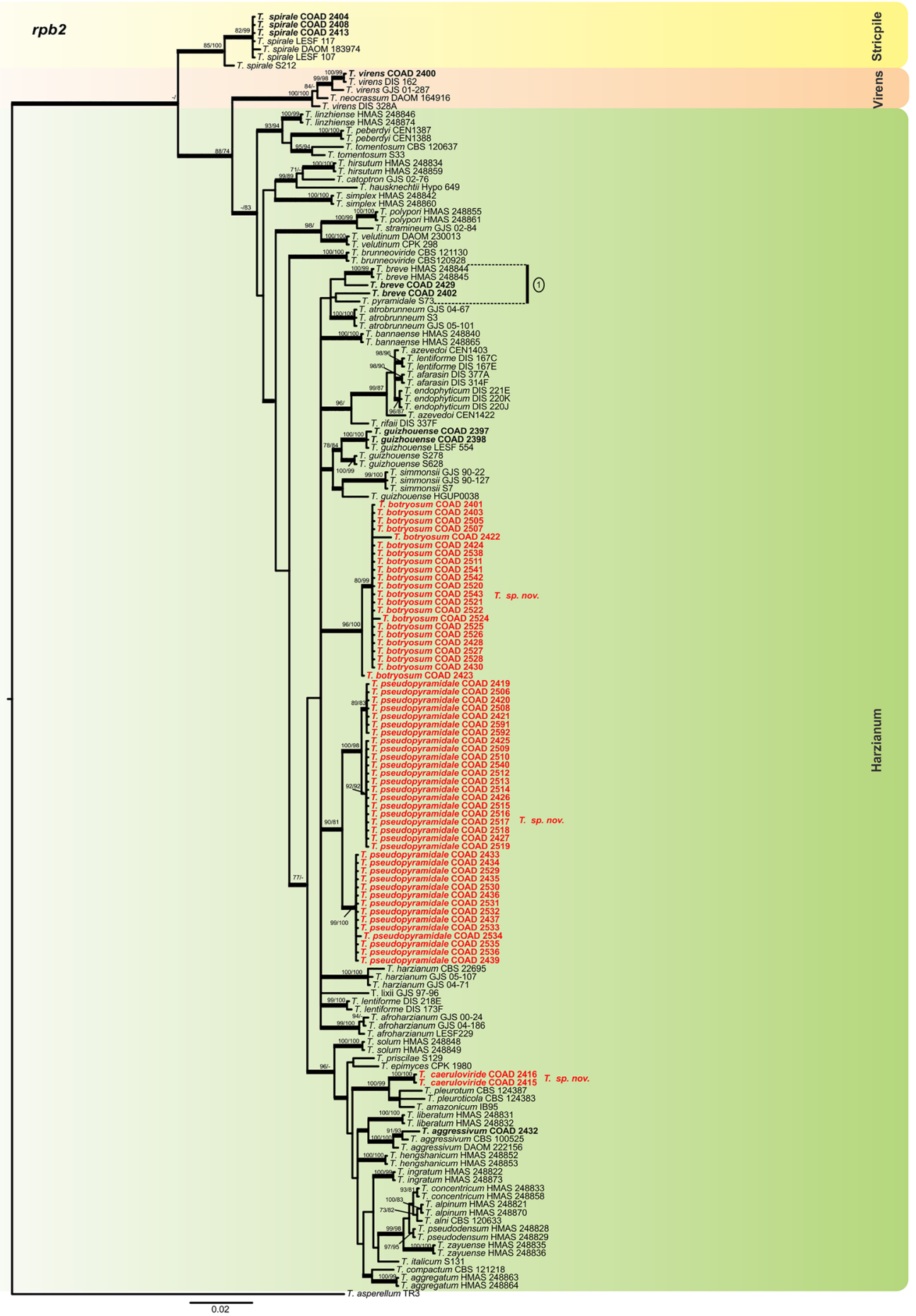

Figure 5. Bayesian phylogenetic tree of clades Harzianum, Strictipile and Virens. The tree was based on rpb2 sequence dataset. Bootstrap values $(\geq 70 \%)$ of the ML analyses, as well as posterior probability scores $(\geq 0.9)$ from a Bayesian analysis of the same dataset, are indicated at well supported nodes together with thickened branches. The isolates belonging to known species, obtained in this study, are in bold. Isolates of new species, described in this study, are in bold red. The tree was rooted with Trichoderma asperellum (TR3). The phylogenetic tree was edited using Inkscape 1.0 (https://inkscape.org/pt-br/).

Notes: Trichoderma aggressivum, in the Harzianum clade, has been reported to cause the green mould epidemic in commercially grown Agaricus bisporus in North America ${ }^{61}$. This is the first report of T. aggressivum as a mycoparasite of Hemileia and of rusts, in general; having been recorded previously only in mushroom farms in both North America and Europe ${ }^{5}$. Thus, this appears to be the first record of T. aggressivum from the tropics. It has been shown to produce various antifungal compounds ${ }^{63}$, and falls within the clade defined by a mycoparasitic mode of nutrition in a consensus phylogenetic tree ${ }^{24}$. 


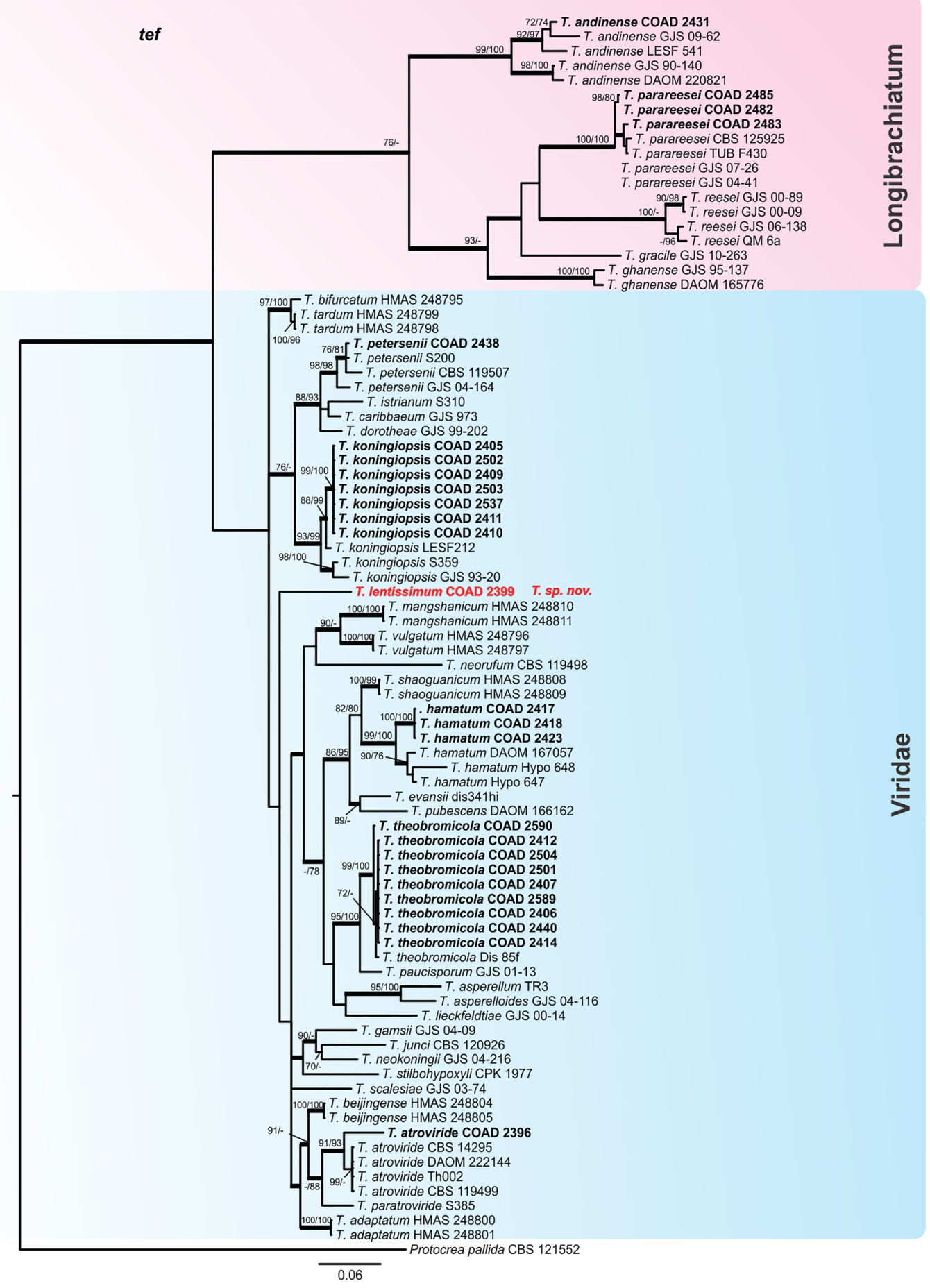

Figure 6. Bayesian phylogenetic tree of clades Longibrachiatum and Viride. The tree was based on tef1 sequence dataset. Bootstrap values $(\geq 70 \%)$ of the ML analyses, as well as posterior probability scores $(\geq 0.9)$ from a Bayesian analysis of the same dataset, are indicated at well supported nodes together with thickened branches. The isolates from known species obtained in this study are in bold. Isolates belonging to new species, described in this study, are in bold red. The tree was rooted with Protocrea pallida (CBS 121552). The phylogenetic tree was edited using Inkscape 1.0 (https://inkscape.org/pt-br/).

Trichoderma andinense (Samuels \& O. Petrini) Samuels, Jaklitsch \& Voglmayr-in Jaklitsch \& Voglmayr, Mycotaxon 126:146, 2014. MycoBank: MB807417.

Synonym: Hypocrea andinensis Samuels \& O. Petrini-in Samuels et al., Stud. Mycol. 41:13, 1998.

Description and illustration, $\operatorname{see}^{2,64}$. 


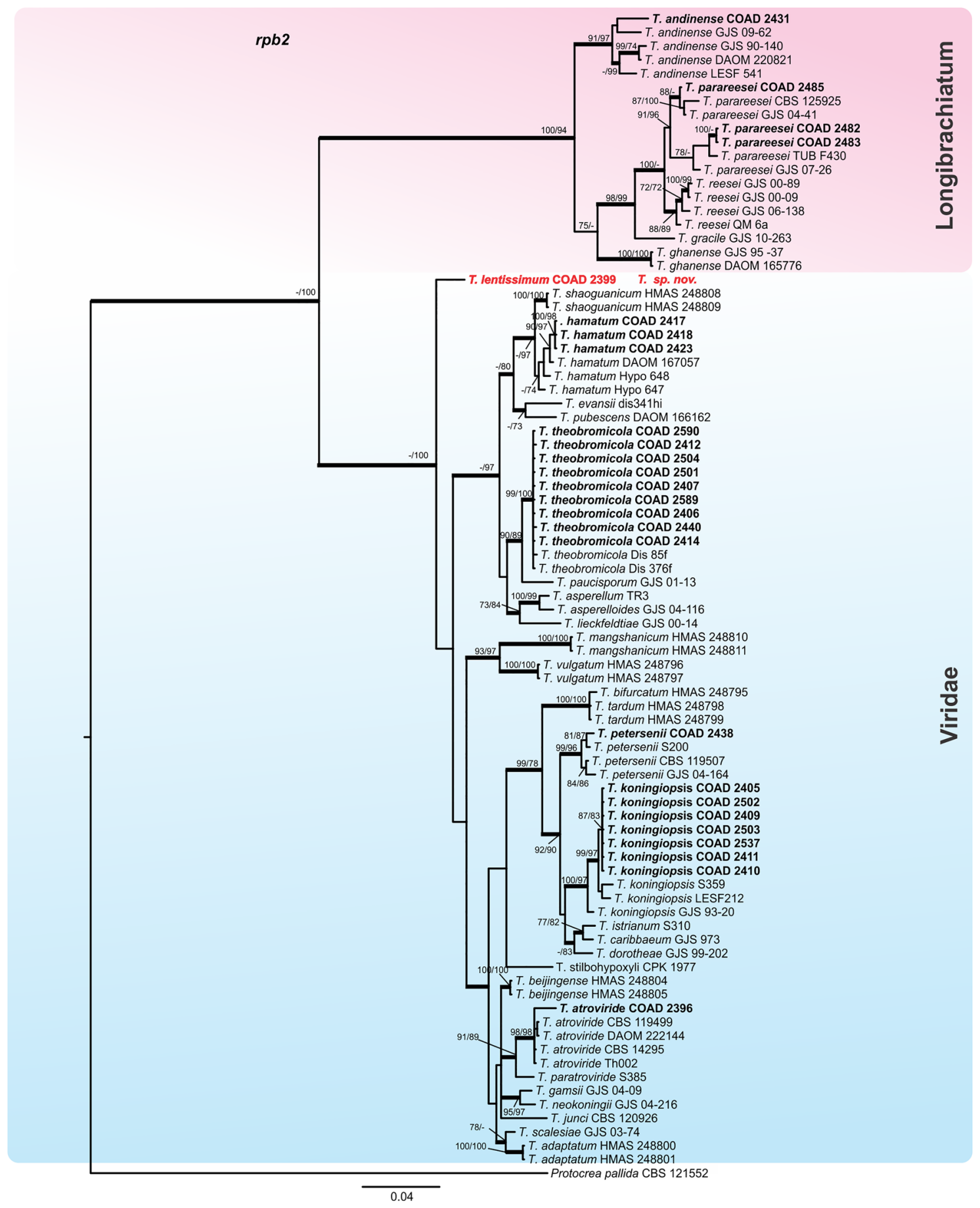

Figure 7. Bayesian phylogenetic tree of clades Longibrachiatum and Viride. The tree was based on rpb2 sequence dataset. Bootstrap values $(\geq 70 \%)$ of the ML analyses, as well as posterior probability scores $(\geq 0.9)$ from a Bayesian analysis of the same dataset, are indicated at well supported nodes together with thickened branches. The isolates belonging to known species, obtained in this study are in bold. Isolates of new species, described in thes study, are in bold red. The tree was rooted with Protocrea pallida (CBS 121552). The phylogenetic tree was edited using Inkscape 1.0 (https://inkscape.org/pt-br/).

Material examined. BRAZIL: Rio de Janeiro, Duas Barras, Fazenda do Campo, Sítio Recanto do Sossego, coffee farm, isolated as a mycoparasite of Hemileia vastatrix on leaves of Coffea arabica, 2 May 2015, R. W. Barreto (culture COAD 2431).

Notes: This fungus, in the Longibrachiatum clade, was originally described from its sexual morph collected from a log in the Venezuelan Andes ${ }^{65}$. Similar isolates from soil in Saudi Arabia, Amazonian Peru and Hawaii were reported later ${ }^{64}$ but were considered to represent new taxa within the T. andinense sub-clade and this species "remains known only from a single collection" ${ }^{64}$. Thus, this is the first report of T. andinense as a mycoparasite of 


\begin{tabular}{|c|c|c|c|c|c|c|c|c|c|c|c|c|}
\hline \multirow[b]{2}{*}{ Species } & \multicolumn{4}{|c|}{ Ethiopia } & \multicolumn{4}{|c|}{ Cameroon } & \multicolumn{4}{|c|}{ Kenya } \\
\hline & Leaf & Stem & Berry & Mycoparasite & Leaf & Stem & Berry & Mycoparasite & Leaf & Stem & Berry & Mycoparasite \\
\hline T. aggressivum & & & & & & & & & & & & 1 \\
\hline T. atroviride & & & & & & & & & 1 & & & \\
\hline T. botryosum sp. nov. & 6 & 11 & 3 & & & 2 & & & & & & \\
\hline T. caeruloviride sp. nov. & & & 2 & & & & & & & & & \\
\hline T. guizhouense & & & & & & & & & & 2 & & \\
\hline T. hamatum & & 2 & 1 & & & & & & & & & \\
\hline T. koningiopsis & & & & & 6 & 1 & & & & & & \\
\hline T. breve & & & 1 & & & 1 & & & & & & \\
\hline T. lentissimum sp. nov. & & & & & & & & & & 1 & & \\
\hline T. parareesei & & 2 & & 1 & & & & & & & & \\
\hline T. petersenii & & & & 1 & & & & & & & & \\
\hline
\end{tabular}

Table 2. Number of taxa collected in this survey per country-source.

\begin{tabular}{|l|l|l|l|}
\hline State & Municipality & Situation/locality & Date \\
\hline Espírito Santo & Domingos Martins & Inside forest fragment, Pedra Azul, Fazenda Camocim & 24 Oct 2019 \\
\hline Espírito Santo & Domingos Martins & Inside forest fragment, INCAPER & 24 Oct 2019 \\
\hline Espírito Santo & Venda Nova do Imigrante & Inside forest reserve, Fazenda Soloença & 24 Oct 2019 \\
\hline Minas Gerais & Cláudio & $\begin{array}{l}\text { Surviving plants of abandoned coffee plantation overgrown by secondary } \\
\text { forest, vicinity of Cládio city }\end{array}$ & 10 Feb 2019 \\
\hline Minas Gerais & São Miguel do Anta & Insided forest reserve in coffee farm, & 9 Oct 2019 \\
\hline Minas Gerais & Viçosa & Inside forest reserve, Mata do Paraíso, Universidade Federal de Viçosa & 19 Feb 2019 \\
\hline Rio de Janeiro & Rio de Janeiro & $\begin{array}{l}\text { Under secondary forest, outskirts of the Parque Nacional da Floresta da } \\
\text { Tijuca }\end{array}$ & 2 Apr 2019 \\
\hline São Paulo & Iporanga & $\begin{array}{l}\text { Row of old plants cultivated close to forest reserve (PETAR), Bairro Serra de } \\
\text { Iporanga }\end{array}$ & 17 Feb 2020 \\
\hline
\end{tabular}

Table 3. Survey sites in Brazil of Coffea arabica, in semi-wild or forest situations, sampled for presence of Trichoderma endophytes.

H. vastatrix, and as a mycoparasite, in general. It was shown to group in a plant saprotrophy clade in the study by Chaverri and Samuels ${ }^{24}$.

Trichoderma atroviride P. Karst.—in Finl. Mögelsvamp. 21, 1892. MycoBank: MB451289.

Synonym: Hypocrea atroviridis Dodd, Lieckfeldt \& Samuels, Mycologia 95:36, 2003.

Description and illustration, see ${ }^{5}$.

Material examined. KENYA: Western Region, Nandi County, Kakamega Forest Reserve, Isecheno, coffee farm, alt $1600 \mathrm{~m}$; isolated as an endophyte from leaf of Coffea arabica, 23 January 2015, H.C. Evans \& R.W. Barreto (culture COAD 2396).

Notes: This is a cosmopolitan species, in the Viride clade, but it is more commonly isolated from soil in tropical regions ${ }^{5}$ and its sexual morph is rarely formed ${ }^{3}$. Chaverri and Samuels ${ }^{24}$ show its habitat preference is soil, but in their phylogenetic tree, T. atroviride groups with species having a mycoparasitic mode of nutrition. In our study, it was isolated from a leaf of C. arabica and this is the first record of T. atroviride as an endophyte of coffee. Trichoderma atroviride is more associated with the plant rhizosphere, rather than aerial tissues, and it has been shown recently that colonization of both maize and tomato roots by this fungus induces foliar herbivory resistance ${ }^{66}$. Previously, it has been known to protect plants against root pathogens (Pythium, Rhizoctonia) through induced resistance and antibiosis ${ }^{67}$.

Trichoderma botryosum M.C.H. Rodríguez, H.C. Evans \& R.W. Barreto sp. nov.-MycoBank: MB832341 (Figs. 8g-i, 9).

Etymology: referring to the grape-like clusters of conidia.

Holotype. ETHIOPIA: Southern Nations, Nationalities and Peoples Region, Kaffa Zone, Bonga District, Gela Wild Coffee Biosphere Reserve, cloud forest, alt $1900 \mathrm{~m}$; isolated as an endophyte from berries of Coffea arabica; 25 November 2015, H.C. Evans, K. Belachew \& R.W. Barreto. Ex-type culture: COAD 2422. GenBank: TEF1 = MK044119; RPB2 = MK044212.

Culture characteristics-Colonies on PDA: Optimum growth temperature at $30^{\circ} \mathrm{C}, 65 \mathrm{~mm}$ after $72 \mathrm{~h}$, $56-61 \mathrm{~mm}$ at $25^{\circ} \mathrm{C}, 25 \mathrm{~mm}$ at $35^{\circ} \mathrm{C}$; covering the plate after $96 \mathrm{~h}$; cottony white aerial mycelium, green sporulation starting from the centre of the plate, with the formation of concentric rings; with a sweet odour but absence of exudates and soluble pigments. Colonies on CMD: Optimum growth temperature at $30^{\circ} \mathrm{C} ; 63 \mathrm{~mm}$ after $72 \mathrm{~h}, 55-58 \mathrm{~mm}$ at $25^{\circ} \mathrm{C}, 43 \mathrm{~mm}$ at $35^{\circ} \mathrm{C}$; mycelium hyaline, poor sporulation, concentric rings absent and no odour. Colonies on SNA: Optimum growth temperature at $30^{\circ} \mathrm{C}, 61 \mathrm{~mm}$ after $72 \mathrm{~h}, 49-53 \mathrm{~mm}$ at $25^{\circ} \mathrm{C}, 28 \mathrm{~mm}$ 


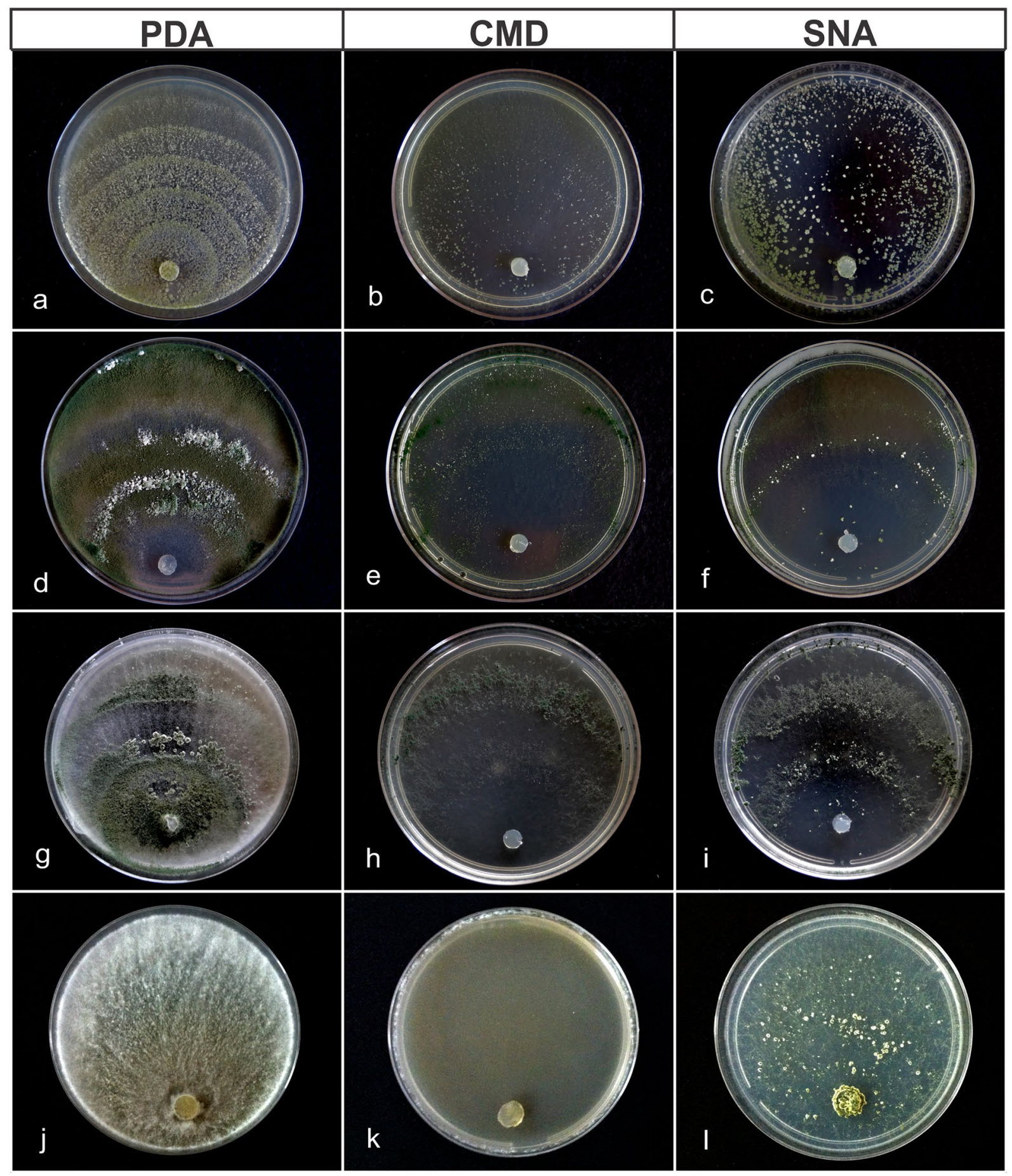

Figure 8. Colony characteristics of the new Trichoderma species on PDA, CMD and SNA. All colonies incubated at $25^{\circ} \mathrm{C}$ under a $12 \mathrm{~h}$ day/night light regime and photographed on day seven. (a-c) T. lentissimum sp. nov..; (d-f) T. caeruloviride sp. nov.; (g-i) T. botryosum sp. nov.; (j-l) T. pseudopyramidale sp. nov.

at $35^{\circ} \mathrm{C}$; mycelium hyaline and smooth, green sporulation; forming concentric rings; exudates and soluble pigments absent.

Conidiophores pyramidal; phialides in whorls or pairs, lateral or terminal, lageniform to ampulliform, 4.0-8.0 $(-8.6) \times(1.9-)$ 2.3-3.1 $\mu \mathrm{m}(\mathrm{L} / \mathrm{W}), 1.2-2.4 \mu \mathrm{m}$ in width at the base; supporting cells 5.4-15.6 $\times 1.8-3.4 \mu \mathrm{m}(\mathrm{L} / \mathrm{W})$; conidia globose to broadly ovoid, 1.4-3.3 $1.6-2.8 \mu \mathrm{m}(\mathrm{L} / \mathrm{W})$, green, smooth; chlamydospores abundant, globose to ellipsoidal, terminal and intercalary, 4.4-8.1 ×3.8-7.3 $\mu \mathrm{m}(\mathrm{L} / \mathrm{W})$.

Notes: Trichoderma botryosum grouped phylogenetically close to T. afarasin and T. endophyticum ${ }^{4}$ in the Harzianum clade. The new species is morphologically similar to its close relatives in: the pyramidal-type conidiophores; size of conidia and ampulliform phialides; and growth rate on PDA at $25^{\circ} \mathrm{C}$. The most distinctive morphological features in this species are the presence of chlamydospores and the grape-like clusters of conidia. 


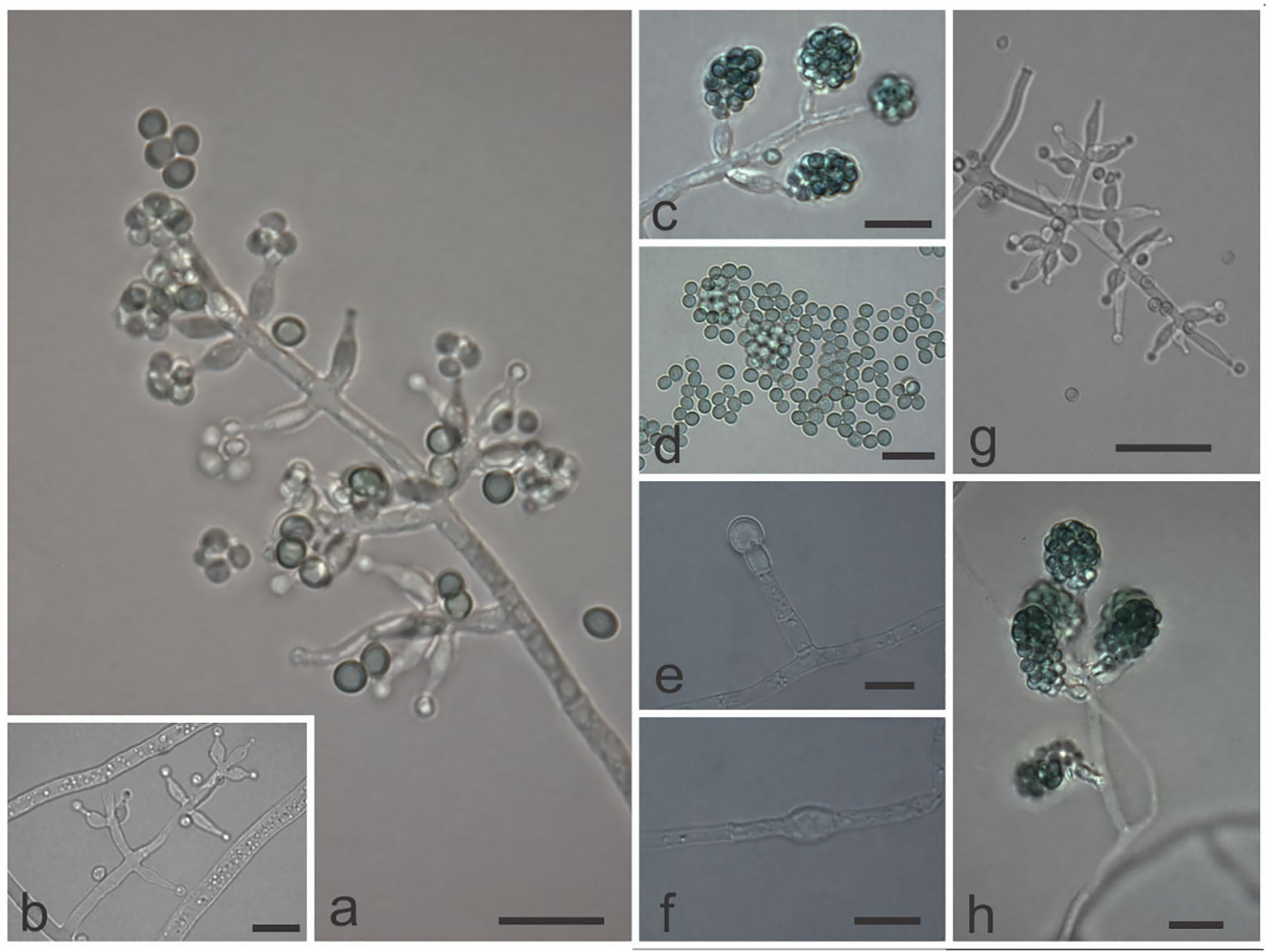

Figure 9. Morphological features characteristic of Trichoderma botryosum sp. nov. (COAD 2422). (a, b, g) Conidiophores and phialides formed on SNA. (c, h) Conidia grouped in bunches. (e, f) Chlamydospores on CMD. (d) Conidia. Bars: $(\mathbf{a}-\mathbf{f}, \mathbf{h})=10 \mu \mathrm{m} ;(\mathbf{g})=20 \mu \mathrm{m}$.

This appears to be a common endophyte of wild C. arabica in Ethiopia; being isolated from all the aerial tissues, with 20 isolates recorded (Table 2). It was uncommon in Cameroon with only two isolates from coffee stems.

Trichoderma breve K. Chen \& W.Y. Zhuang-Chen \& Zhuang., Sci. Rep. 7 (no. 9090): 7, 2017. MycoBank: MB809992.

Description and illustration, $\operatorname{see}^{12}$.

Material examined. CAMEROON: South-West Province, Busumbo, Mt. Etinde, coffee farm, 450 m; isolated as endophyte from stem of Coffea canephora, 17 November 2015, H.C. Evans, R.W. Barreto \& M. K. Ndacnou (culture COAD 2402). ETHIOPIA: Southern Nations, Nationalities and Peoples Region, Kaffa Zone, Bonga District, Komba Wild Forest Reserve, cloud forest, $2000 \mathrm{~m}$; isolated as an endophyte from a berry of Coffea arabica, 25 November 2015, H.C. Evans, R.W. Barreto \& K. Belachew (culture COAD 2429).

Notes: Trichoderma breve is similar morphologically to the T. harzianum complex, and has previously been isolated from soil in the north of China ${ }^{12}$. Phylogenetic analyses indicate that T. breve is closely related to $T$. bannaense $e^{12}$, and in our study it lies close to T. lentiforme. This is the first report of T. breve in Africa and also as an endophyte of coffee; being recorded from both C. canephora and C. arabica in Cameroon and Ethiopia, respectively, with a single isolate from each country (Table 2).

Trichoderma caeruloviride M.C.H. Rodríguez, H.C. Evans \& R.W. Barreto, sp. nov. -Mycobank: MB832340 (Figs. 8d-f, 10).

Etymology: referring to the blue-green colour of the conidial mass.

Holotype: ETHIOPIA: Southern Nations, Nationalities and Peoples Region, Kaffa Zone, Bonga District, Gedam Village, coffee farm, alt $1550 \mathrm{~m}$; isolated as an endophyte from berries of Coffea arabica. 25 November 2015, H.C. Evans, K. Belachew \& R.W. Barreto. Ex-type culture: COAD 2415. GenBank: TEF1= MK044109; $\mathrm{RPB} 2=\mathrm{MK} 044202$.

Culture characteristics-Colonies on PDA: Optimum growth at $25^{\circ} \mathrm{C}, 51-53 \mathrm{~mm}$ after $72 \mathrm{~h}, 34 \mathrm{~mm}$ at $30^{\circ} \mathrm{C}$, no growth at $35^{\circ} \mathrm{C}$, covering the plate after $96 \mathrm{~h}$; mycelium white, aerial, low with green sporulation, no formation of concentric rings; lacking pigmentation and odour. Colonies on CMD: Optimum growth temperature at $25^{\circ} \mathrm{C}$, $42-44 \mathrm{~mm}$ after $72 \mathrm{~h}, 19 \mathrm{~mm}$ at $30^{\circ} \mathrm{C}$, no growth at $35^{\circ} \mathrm{C}$; mycelium hyaline, poor sporulation, green conidia, no concentric rings present and no odour. Colonies on SNA: Optimum growth temperature at $25^{\circ} \mathrm{C}, 29-36 \mathrm{~mm}$ after $72 \mathrm{~h}, 12 \mathrm{~mm}$ at $30^{\circ} \mathrm{C}$, no growth at $35^{\circ} \mathrm{C}$; mycelium hyaline and smooth, poor sporulation; green to blue conidia, with the formation of concentric rings; no pigmentation in the medium.

Conidiophores pyramidal with verticillate, paired lateral branches; phialides generally formed on terminal branches, in divergent whorls of three to four, (5.2-) 5.3-12.2 (-13.2) $\times(1.7-) 2.0-2.8(-3.48) \mu \mathrm{m}$, mean 


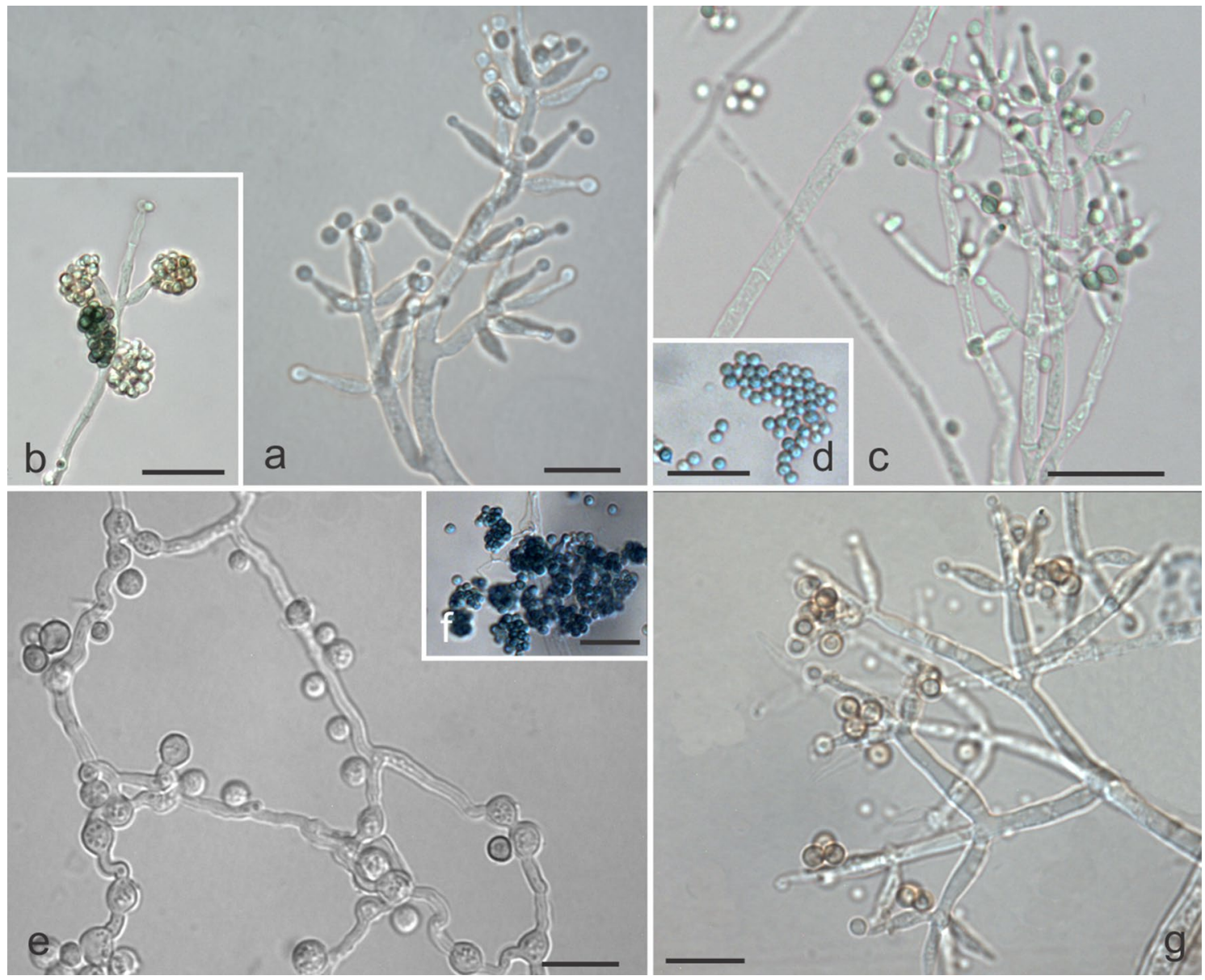

Figure 10. Morphological features characteristic of Trichoderma caeruloviride sp. nov. (COAD 2416). (a, b, c, g) Conidiophores and phialides formed on SNA and CMD. e chlamydospores on CMD. (f, d) Blue conidia. Bars: $(\mathbf{a}, \mathbf{e}, \mathbf{g})=10 \mu \mathrm{m} ;(\mathbf{b}-\mathbf{d}, \mathbf{f})=20 \mu \mathrm{m}$.

$7.4 \times 2.5 \mu \mathrm{m}(\mathrm{L} / \mathrm{W})$; supporting cells $(5.4-)$ 7.9-9.7 $(-10.1) \times 1.7-2.0(-3.0) \mu \mathrm{m}$, mean $8.5 \times 1.9 \mu \mathrm{m}(\mathrm{L} / \mathrm{W})$; conidia ellipsoidal to ovoid, green, smooth, 2.2-3.0 (-3.2) $\times(1.9-) 2.3-3.1(-3.4) \mu \mathrm{m}$, mean $2.8 \times 2.8 \mu \mathrm{m}$ (L/W); chlamydospores terminal and intercalary, globose, 3.3-5.0 $(-6.6) \times 3.0-4.6(-5.3) \mu \mathrm{m}$, mean $4.4 \times 3.7 \mu \mathrm{m}$ (abundantly formed on CMD after 4 days).

Notes: Phylogenetic analyses placed T. caeruloviride close to T. amazonicum ${ }^{8}$ and T. pleuroticola ${ }^{68}$ in the Harzianum clade. The new species can be distinguished from its nearest relatives by: no growth at $35^{\circ} \mathrm{C}$; the presence of a coconut-like odour on PDA; and the blue-green conidia in SNA microculture. Morphologically, $T$. caeruloviride is distinct from T. amazonicum which has a branching pattern of the pachybasium type, elliptical to subglobose conidia, ampulliform phialides, and chlamydospore-like structures in clusters. Trichoderma caeruloviride shares some morphological characteristics with T. pleuroticola, such as the pyramidal-type branching pattern, the globose conidia and the formation of chlamydospores; but can be separated by the larger, lageniform phialides of T. caeruloviride. Both isolates were from berries of C. arabica in Ethiopia and it appears to be a rare species (Table 2).

Trichoderma guizhouense Q.-R. Li, E.H.C. McKenzie \& Yong Wang-in Li et al., Mycol. Prog. 12:170, 2012. MycoBank: MB563664.

Description and illustration, see ${ }^{4,55}$.

Material examined. KENYA: Eastern Province, Marsabit National Park. Lake Paradise, primary forest, alt $1340 \mathrm{~m}$; isolated as an endophyte from stem of Coffea sp. (wild population close to C. arabica and C. canephora, but identity uncertain, even after examination by an authority on the genus Coffea) H.C. Evans \& R.W. Barreto, 28 January 2015 (cultures COAD 2397 and COAD 2398).

Notes: Trichoderma guizhouense, in the Harzianum clade, was first isolated from soil in Guizhou Province of China $^{55}$, and has since shown promise as a biocontrol agent of Rhizoctonia root rot $^{69}$. It was also isolated as an endophyte from the woody liana, Ancistrocladus korupensis (Ancistrocladaceae) - extracts of which are active against $\mathrm{HIV}^{70}$ - and from the sapwood of Cola spp. (Malvaceae) in rainforest of the Cameroon Republic ${ }^{4}$ (H.C. Evans unpubl.). This is the first report of T. guizhouense as a coffee endophyte.

Trichoderma hamatum (Bonord.) Bainier-Bull. Soc. Mycol. Fr. 22:131, 1906. MycoBank: MB165799. 
Synonyms: Verticillium hamatum Bonord., Handb. Allgem. Mykol.: 97, 1851. Pachybasium hamatum (Bonord.) Sacc., Rev. Mycol. Toulouse 7:161, 1885. Phymatotrichum hamatum (Bonord.) Oudem., Ned. Kruidk. Archf. 3:908, 1903.

Description and illustration, see ${ }^{3,5}$.

Material examined. ETHIOPIA: Southern Nations, Nationalities and Peoples Region, Kaffa Zone, Bonga District, Gedam Village, coffee farm, alt $1550 \mathrm{~m}$, isolated as an endophye from stems of Coffea arabica, 25 November 2015, H.C. Evans, R.W. Barreto \& K. Belachew (cultures COAD 2418 and COAD 2417). ETHIOPIA: Southern Nations, Nationalities and Peoples Region, Kaffa Zone, Bonga District, Gela Wild Coffee Biosphere Reserve, cloud forest, alt $1700 \mathrm{~m}$; isolated as an endophyte from berry of Coffea arabica, 25 November 2015, H.C. Evans, R.W. Barreto \& K. Belachew (COAD 2423).

Notes: Trichoderma hamatum, in the Viride clade, is a cosmopolitan species, originally isolated from soil but it has also been reported as an endophyte in both stems and pods of wild Theobroma gileri from sub-montane forest in western Ecuador ${ }^{20}$. In addition, it was identified as a mycoparasite of frosty pod disease (Moniliophthora roreri) on the same host in this ecosystem ${ }^{20}$. It has also been isolated from the rhizosphere of C. arabica in Ethiopia ${ }^{15}$. In our study, T. hamatum was obtained from stems and berries of C. arabica in both cultivated and wild coffee plants, also in Ethiopia. It is most frequently cited as a colonizer of the rhizosphere, and some soil strains have been shown to promote crop growth, to activate biocontrol mechanisms against root pathogens and to induce systemic resistance to foliar pathogens ${ }^{71}$. Previously, an endophyte strain from the pod of a wild Theobroma species was found to promote the growth and delay drought symptoms in cacao plants ${ }^{72}$.

Trichoderma koningiopsis Samuels, C. Suárez \& H.C. Evans-in Samuels et al., Stud. Mycol. 56:117, 2006. MycoBank: MB487454.

Description and illustration, $\mathrm{see}^{5,60}$

Material examined. CAMEROON: Eastern Province, Zemele Village, coffee farm, alt $660 \mathrm{~m}$; isolated as an endophyte from leaves of Coffea canephora, 22 November 2015, H.C. Evans, R.W. Barreto \& M. K. Ndacnou (Cultures COAD 2537; COAD 2405; COAD 2502; COAD 2503; COAD 2410; COAD 2411 and COAD 2409).

Notes: Trichoderma koningiopsis, in the Viride clade, is a cosmopolitan species, but it is more frequently recorded in tropical rather than temperate regions, and mostly from soil. During a survey of Trichoderma diversity in soil and leaf litter from the Amazonian rainforest of Colombia, T. koningiopsis was amongst the commonest species isolated ${ }^{73}$. In the Atlantic rainforest of Brazil, T. koningiopsis was found to be the dominant Trichoderma species in leaves being carried by Atta leaf-cutting ants, and subsequently rejected by them from the nest: it was posited that the ants recognized the threat posed by this mycoparasite to the fungal garden ${ }^{74}$. It has also been reported as a common stem endophyte in a species of Theobroma in sub-montane forest in western Ecuador $^{22}$. It has also been shown to colonize cacao plants via the leaf trichomes ${ }^{75}$. An isolate of Trichoderma koningiopsis from the stem of a Vinca species in Iran was found to produce a range of anti-microbials, including trichodermin, as well as cytotoxic compounds ${ }^{76}$. Trichoderma koningiopsis has also previously been isolated from the rhizosphere of C. arabica in Ethiopia ${ }^{15}$. Here, it is reported for the first time as an endophyte of Coffea: all seven isolates being recovered from the leaves and stem of both cultivated and wild C. canephora in Cameroon (Table 2), where it appears to be common.

Trichoderma lentissimum M.C.H. Rodríguez, H.C. Evans \& R.W. Barreto sp. nov. Mycobank: MB832339 (Figs. 8a-c, 11).

Etymology: referring to its slow growth in culture.

Holotype: KENYA: Eastern Province, Marsabit National Park, Lake Paradise, primary forest, alt $1340 \mathrm{~m}$; isolated as an endophyte from stem of Coffea cf. arabica, 28 January 2015, H.C. Evans \& R.W. Barreto. Ex-type culture: COAD 2399. Genbank: TEF1 = MK044086; RPB2 = MK044179.

Culture characteristics-Colonies on PDA: Optimum growth temperature at $25^{\circ} \mathrm{C}, 28-30 \mathrm{~mm}$ after $72 \mathrm{~h}$, $7 \mathrm{~mm}$ at $30^{\circ} \mathrm{C}$, no growth at $35^{\circ} \mathrm{C}$; at $25^{\circ} \mathrm{C}$ mycelium mostly on surface, greyish-white aerial, olive-green sporulation, beginning in the colony centre with the formation of concentric rings; no pigmentation in the medium; odour lacking. Colonies on CMD: Optimum growth temperature at $25^{\circ} \mathrm{C}, 29-31 \mathrm{~mm}$ after $72 \mathrm{~h}, 1 \mathrm{~mm}$ at $30^{\circ} \mathrm{C}$, no growth at $35^{\circ} \mathrm{C}$; mycelium mainly hyaline, low with olive-green sporulation, no formation of concentric rings, lacking pigmentation and odour. Colonies on SNA: Optimum growth temperature at $25^{\circ} \mathrm{C}, 30 \mathrm{~mm}$ after $72 \mathrm{~h}$, $9 \mathrm{~mm}$ at $30^{\circ} \mathrm{C}$, no growth at $35^{\circ} \mathrm{C}$; mycelium hyaline and smooth, low with olive-green sporulation; absence of concentric rings and no pigmentation; forming amorphous and cottony pustules, $1-3.5 \mathrm{~mm}$ in diam.

Conidiophores pyramidal with phialides in whorls; phialides lageniform, (4-) 5-9.7 (-10.7) $\times(1.9-)$ 2-3 (-3.2) $\mu \mathrm{m}$, mean $7.6 \times 2.7 \mu \mathrm{m}(\mathrm{L} / \mathrm{W})$; supporting cells (4.9-) 5.7-11.9 (-12.5) $\times(1.6-) 1.7-2.9(-3) \mu \mathrm{m}$, mean $8.1 \times 2.1 \mu \mathrm{m}$ $(\mathrm{L} / \mathrm{W})$; conidia globose to broadly ellipsoid, $2.2-3.9(-4.3) \times(1.9-) 2-2.9(-3.2) \mu \mathrm{m}$, mean $2.8 \times 2.6 \mu \mathrm{m}$, greencoloured, smooth; chlamydospores globose to subglobose, abundant, intercalary and terminal, (5.4-) 6.9-12.3 $(-13.5) \times(3.6-4-7.1(-10.2) \mu \mathrm{m}$, mean $9.4 \times 6.6 \mu \mathrm{m}$ on CMD and PDA.

Notes: Trichoderma lentissimum is phylogenetically close to T. gamsii $^{77}$ and T. lieckfeldtiae ${ }^{38}$ in the Viride clade. The new species is also morphologically similar to T. gamsii in: the branching pattern (pyramidal type); the lageniform phialides; and the formation of chlamydospores; but can be separated based on the smaller phialides and conidia of T. lentissimum as compared with those of T. gamsii. The most prominent differences between $T$. lentissimum and T. lieckfeldtiae, is the pachybasium-type branching pattern which is found only in T. lieckfeldtiae and the absence of chlamydospores in the latter. This species appears to be rare and it was only isolated once during the survey, as a stem endophyte in Kenya.

Trichoderma parareesei Jaklitsch, Druzhin. \& Atanasova-in Atanasova et al. Appl. Environ. Microbiol. 76:7261, 2010. MycoBank: MB515503.

Description and illustration, see ${ }^{59}$.

In a paper of the same year $(2010)^{78}$, this species is listed as T. parareesei nom. prov. and, subsequently, registered as T. parareesei sp. nov.. Jaklitsch, Druzhinina \& Atanasova in MycoBank ${ }^{59}$. However, the authorities 


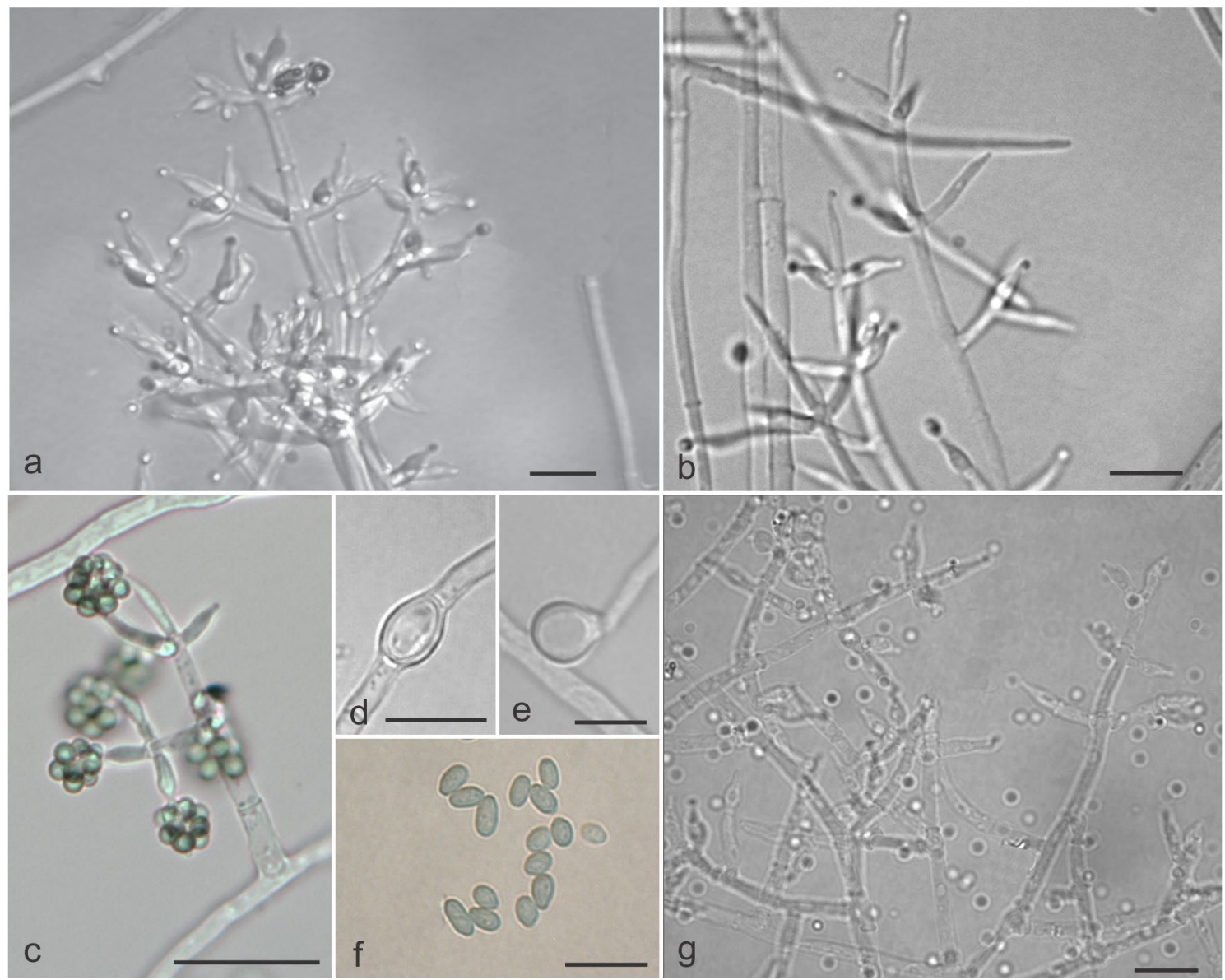

Figure 11. Morphological features characteristic of Trichoderma lentissimum sp. nov. (COAD 2399). (a-c, g) Conidiophores and phialides formed on SNA and CMD. (d, e) Chlamydospores on CMD. (f) Conidia. Bars: (a, b, $\mathbf{d}-\mathbf{f})=10 \mu \mathrm{m} ;(\mathbf{c}, \mathbf{g})=20 \mu \mathrm{m}$.

in MycoBank are cited erroneously as Jacklitsch \& Atanasova and, even more bizarrely, as Atan., Jaklitsch, Komoń-Zel., C.P. Kubicek \& Druzhin. in Index Fungorum; whilst Bissett et al. ${ }^{52}$ give the authorities as Atanasova, Jaklitsch, Komon-Zelazowska, C.P. Kubicek \& Druzhinina. Moreover, both the latter two quote the wrong citation page, 7259 instead of 7261 . The correct citation, as given above, has been confirmed by the editor of Index Fungorum (P.M Kirk pers. comm., 22 January 2020), and the IF database will be amended, accordingly.

Material examined. ETHIOPIA: Southern Nations, Nationalities and Peoples Region, Kaffa Zone, Bonga District, Komba Wild Forest Reserve, cloud forest, alt $2000 \mathrm{~m}$; isolated as a mycoparasite of Hemileia cf. coffeicola, from leaf of Coffea arabica, 19 January 2018, H.C. Evans \& K. Belachew (culture COAD 2483); Ibid, Maakira, coffee farm, alt $1450 \mathrm{~m}$; isolated as an endophyte from stem of Coffea arabica, 21 January 2018, H.C. Evans \& K. Belachew (culture COAD 2482); Kaffa Zone, Gesha District, coffee farm, alt $1600 \mathrm{~m}$; isolated as an endophyte from stem of Coffea arabica, 22 January 2018, H.C. Evans \& K. Belachew (culture COAD 2485).

Notes: Trichoderma parareesei, in the Longibrachiatum clade, was originally isolated from soil of a subtropical rainforest near Iguazu Falls, Argentina, and is reported to have a pantropical distribution in both rainforest and agricultural soils ${ }^{59,64}$. During a survey of Trichoderma species in the sapwood and dead branches of cacao trees in south-eastern Brazil, it was exclusively isolated from dead wood-where it was the dominant species-and was never recorded from the sapwood ${ }^{79}$. In our study, T. parareesei was isolated as an endophyte from stems of C. arabica and also as a mycoparasite of Hemileia cf. coffeicola. This species has never been reported before either as an endophyte in coffee or as a mycoparasite, and probably this is the first record as an endophyte, in general $\left(\mathrm{see}^{79}\right)$. Trichoderma parareesei was described as a sympatric, clonal, agamospecies (reproducing only asexually) closely related to T. reesei and is its likely ancestor ${ }^{59,78}$. The latter is a critically important species in the biotechnology industry as a producer of cellulases and hemicellulases and-because of its ability to express recombinant proteins-it is now being targeted for a role in the production of biofuels ${ }^{80}$. Many of these industrial strains have been shown to be T. parareesei by Druzhinina et al. ${ }^{78}$. They also found that this species is strongly mycoparasitic, compared to T. reesei, showing significant antagonism to a range of aerial plant pathogens in dual-culture tests. It has also been demonstrated that $T$. parareesei has biocontrol potential against both fungal and oomycete plant pathogens and, moreover, that it enhances root development and promotes growth, in general, of tomato plants ${ }^{81}$. Finally, it was posited that the ecological niche of $T$. parareese $i$ is not soil but the canopy of tropical forest ${ }^{78}$. Our results confirm their supposition since this species was recorded in stems of wild to semi-wild C. arabica, as well 
as being found as a mycoparasite of Hemileia rust in the canopy of wild coffee trees in the understorey of cloud forest: all isolates from Ethiopia (Tables 1 and 2).

Trichoderma petersenii Samuels, Dodd \& Schroers-in Samuels et. al., Stud. Mycol. 56:122, 2006. MycoBank: MB501043.

Synonym: Hypocrea petersenii Samuels, Dodd \& Schroers. Samuels et al., Stud. Mycol. 56:122, 2006.

Description and illustration, see ${ }^{60}$.

Material examined. ETHIOPIA: Southern Nations, Nationalities and Peoples Region, Kaffa Zone, Bonga District, Komba Wild Forest Reserve, cloud forest, alt $1900 \mathrm{~m}$; isolated as a mycoparasite of Hemileia cf. coffeicola on leaf of Coffea arabica, 26 November 2015, H.C. Evans \& R.W. Barreto (culture COAD 2438).

Notes: With the exception of the soil isolate DAOM 165782 (North Carolina), T. petersenii was known previously only from ascospore isolations ${ }^{60}$. However, it has since shown to be common on woody hosts in Southern Europe, especially in Spain, and is reported to be ubiquitous on the Canary Islands, being found in the sexual stage on stromata of the Xylariaceae ${ }^{3}$, presumably as a mycoparasite. In our study, T. petersenii was found for the first time in Africa, and also this is the first report of it as a rust mycoparasite, specifically, on a Hemileia species close to H. coffeicola (Table 1). The latter species, however, is a pathogen of C. canephora in the lowland tropics of West Africa and thus this high-altitude rust of wild Arabica coffee in Ethiopia is considered to be undescribed.

Trichoderma pseudopyramidale M.C.H. Rodríguez, H.C. Evans \& R.W. Barreto sp. nov.-Mycobank: MB832342 (Figs. 8j-1, 12).

Etymology: indicating its phylogenetic proximity to T. pyramidale.

Holotype: ETHIOPIA: Southern Nations, Nationalities and Peoples Region, Kaffa Zone, Bonga District, Maakira-Grugutto, semi-wild coffee farm, alt $1600 \mathrm{~m}$; isolated as an endophyte from leaves and stems of Coffea arabica, 25 November 2015, H.C. Evans \& R.W. Barreto. Ex-type culture: COAD 2426.

Culture characteristics-Colonies on PDA: Optimum growth temperature at $25^{\circ} \mathrm{C}, 43-45 \mathrm{~mm}$ after $72 \mathrm{~h}$, $40 \mathrm{~mm}$ at $30^{\circ} \mathrm{C}, 22 \mathrm{~mm}$ at $35^{\circ} \mathrm{C}$, covering the plate after $96 \mathrm{~h}$; mycelium cream, concentric rings absent and no odour; yellow pigmentation in the central reverse of plate. Colonies on CMD: Optimum growth temperature at $25^{\circ} \mathrm{C}$ and $30^{\circ} \mathrm{C}, 43-44 \mathrm{~mm}$ after $72 \mathrm{~h}, 44 \mathrm{~mm}$ at $30^{\circ} \mathrm{C}, 25 \mathrm{~mm}$ at $35^{\circ} \mathrm{C}$; mycelium hyaline, no sporulation, absence of concentric rings and odour. Colonies on SNA: Optimum growth temperature at $25^{\circ} \mathrm{C}, 40-42 \mathrm{~mm}$ after $72 \mathrm{~h}, 33 \mathrm{~mm}$ at $30^{\circ} \mathrm{C}, 23 \mathrm{~mm}$ at $35^{\circ} \mathrm{C}$; mycelium hyaline and smooth, sporulation sparse; absence of concentric rings and pigmentation; forming amorphous, cottony pustules, measuring $1-3.5 \mathrm{~mm}$ in diam, turning yellowish then dark green centrally.

Conidiophores pyramidal- to tree-type; phialides ampulliform to lageniform, usually formed in whorls, (5-) 5.3-8.6 (-9.1) ×(1.9-) 2.2-2.9 (-3.2) $\mu \mathrm{m}$, mean $6.4 \times 2.6 \mu \mathrm{m}(\mathrm{L} / \mathrm{W})$, base (1.3-) 1.3-2.3 (-2.5) $\mu \mathrm{m}$ wide; supporting cells $(2.5-)$ 3.3-7.1 $(-8.2) \times 1.9-2.8(-3.2) \mu \mathrm{m}$, mean $6 \times 2.5 \mu \mathrm{m}(\mathrm{L} / \mathrm{W})$; conidia globose, sub-globose or ovoid, green, smooth, (1.8-) 2.1-2.9 $\times(2.1-)$ 2.3-2.9 (-3.2) $\mu$ m, mean $2.5 \times 2.6 \mu \mathrm{m}(\mathrm{L} / \mathrm{W})$; chlamydospores globose to sub-globose (3.21-) 3.2-8.1 (-9.07) × (3.5-) 3.9-7.5 (-8.5) $\mu \mathrm{m}$, mean $6.0 \times 6.1 \mu \mathrm{m}(\mathrm{L} / \mathrm{W})$.

Additional strain examined: CAMEROON: Eastern Province, Somalomo Village, coffee farm, alt $700 \mathrm{~m}$; isolated as a mycoparasite from pustules of Hemileia coffeicola on leaves of Coffea canephora, 22 November 2015, H.C. Evans and R.W. Barreto, COAD 2433. GenBank: TEF1= MK044131, MK044157; RPB2=MK044224, MK044250; $C A L=$ MK084870, MK084869.

Notes: Most of the species found in this study could be identified with high support using the combination of tef1 and $r p b 2$ genes. However, for the isolates assigned to T. pseudopyramidale, it was also necessary to include the calmodulin gene in the analysis in order to separate the novel species from the closely related T. pyramidale. Trichoderma pseudopyramidale grouped phylogenetically close to T. pyramidale in the Harzianum clade. The two species share several characteristics in common, such as pyramidal conidiophores, a similar growth rate on PDA and SNA, and the formation of amorphous pustules with white-yellow borders. Trichoderma pyramidale has larger phialides and conidia, compared to T. pseudopyramidale, whilst the latter species forms chlamydospores on CMD and produces a yellow reverse on PDA; and, unlike T. pyramidale, it is able to grow at $35^{\circ} \mathrm{C}$. Trichoderma pseudopyramidale forms two monophyletic subclades, one containing endophytic isolates and another including isolates obtained directly from CLR pustules (as mycoparasites). Since both subclades come from a phylogenetically well-supported clade by ML, MP and BI, we decided to keep them in a single species and consider them to represent an infra-specific grouping not warranting taxonomic recognition at this stage. No significant differences in morphology or in the growth rates for isolates belonging to these subclades were found. In our study, T. pseudopyramidale represented by far the commonest isolate ( 35 isolates), the greater majority as an endophyte in both stems and leaves of C. arabica, as well as a mycoparasite of Hemileia cf. coffeicola on wild Arabica coffee in Ethiopia (Tables 1 and 2). There was a single record from Cameroon, as a mycoparasite of Hemileia coffeicola on C. canephora.

Trichoderma spirale Bissett-Can. J. Bot. 69:2408, 1991. MycoBank: MB359087 Description and illustration, see $^{5}$.

Material examined. CAMEROON: Eastern Province, Somalomo, Dja Forest Reserve, rainforest, alt $700 \mathrm{~m}$; isolated as an endophyte from stems of C. canephora, 21 November 2015, H.C. Evans \& R.W. Barreto (cultures COAD 2408; COAD 2404 and COAD 2413).

Notes: Trichoderma spirale, in the Strictipile clade, is a cosmopolitan species. It was isolated for the first time from soil in Thailand, but has since found to be common in sapwood of cacao and other Theobroma spp. ${ }^{79,82}$. It was also the dominant Trichoderma species isolated from roots of Pinus densiflora in South Korea and it was suggested that Trichoderma may be playing a role in stimulating plant colonization by the ectomycorrhizal fungus Tricholoma matsutake 83 . In our study, it was found for the first time as an endophyte of coffee; all three isolates were from stems of wild C. canephora in Cameroon rainforest of the Congo basin.

Trichoderma theobromicola Samuels \& H.C. Evans-in Samuels et al., Mycol. Res. 110:390, 2006. MycoBank: MB356642. 

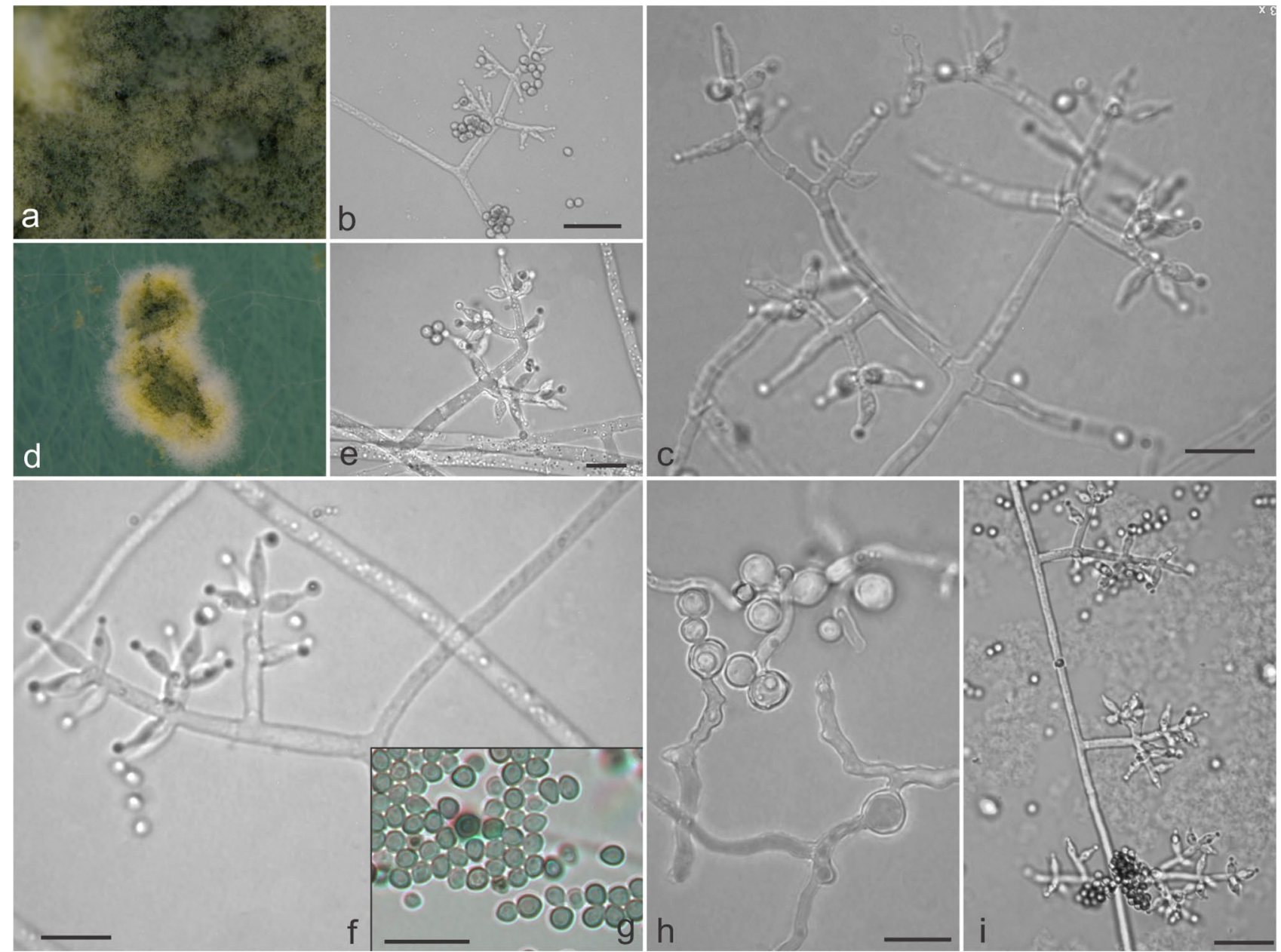

Figure 12. Morphological features characteristic of Trichoderma pseudopyramidale sp. nov. (COAD 2426). (a, d) Stereo microscope images on SNA. (b, c, e, f, i) Conidiophores and phialides formed on SNA. (h) chlamydospores on CMD. (g) Conidia. Bars: (e, c, f, h) $=10 \mu \mathrm{m} ;(\mathbf{b}, \mathbf{i})=20 \mu \mathrm{m}$.

Description and illustration, see ${ }^{22}$.

Material examined. CAMEROON: Eastern Province, Somalomo, Dja Forest Reserve, rainforest, $700 \mathrm{~m}$; as an endophyte from stems of Coffea canephora, 21 November 2015, H.C. Evans \& R.W. Barreto (cultures COAD 2406; COAD 2407; COAD 2501; COAD 2504; COAD 2412; COAD 2440; COAD 2414; COAD 2589 and COAD 2590).

Notes: Trichoderma theobromicola, in the Viride clade, was found for the first time growing as an endophyte in the trunk of wild cacao in Amazonian Peru and, in subsequent greenhouse studies, it demonstrated promise as an antagonist against frosty pod disease (Moniliophthora roreri) after being inoculated into and re-isolated from seedlings of $\mathrm{cacao}^{22}$. Similarly, an isolate of T. theobromicola from Cola sp. in the Cameroon ${ }^{38}$ revealed biocontrol potential after it was shown to be parasitic on and reduced the disease incidence of Phytophthora in Capsicum annuит ${ }^{84}$. All the isolates in our study were from stems of wild C. canephora in Cameroon rainforest (Table 1). This is the first report of this species as an endophyte of coffee.

Trichoderma virens (J.H. Hill, Giddens \& A.A. Foster) Arx-Nova Hedwig. Beih. 87: 288, 1987. MycoBank: MB128198.

Synonym: Gliocladium virens J.H. Mill., Giddens \& A.A. Foster, Mycologia 49:792, 1957.

Description and illustration, see $^{5}$.

Material examined. CAMEROON: South-West Province, Ekonjo, Mt. Etinde, rainforest, alt $700 \mathrm{~m}$; isolated as an endophyte from stem of wild Coffea brevipes, 17 November 2015, H.C. Evans, R.W. Barreto \& M.K. Ndacnou (culture COAD 2400).

Notes: Trichoderma virens is a cosmopolitan species, commonly isolated from soil samples, but its sexual morph appears to be rare; having been found only once on dead wood ${ }^{5}$. In our study, it was isolated from the stem of a wild species of Coffea in Cameroonian rainforest on a single occasion. This is the first record of $T$. virens as an endophyte of coffee and, seemingly, as an endophyte of aerial plant tissues. Previously, it has been shown to colonize sugar-cane roots; forming dense mycelium in the intercellular spaces ${ }^{85}$. It was also reported that $T$. virens secretes proteins to facilitate colonization of maize roots in which plant-host immune responses are suppressed ${ }^{86}$. Earlier, it was demonstrated that $T$. virens promotes growth of Arabidopsis by stimulating the 
root system through an auxin-dependent mechanism ${ }^{87}$. The isolate from our study may have additional mechanisms to colonize woody stems and, perhaps, to form a similar beneficial interaction with its wild coffee host.

\section{Discussion}

Previous studies have investigated the diversity of endophytic fungi associated with coffee ${ }^{88-92}$, but these were based on surveys restricted to the Americas and Hawaii, where coffee is an exotic introduced species. The endophytic mycobiota found in these studies is dominated by genera such as Colletotrichum, Fusarium, Penicillium, Pestalotia and Xylaria. Such assemblages consist mainly of opportunistic endophytes-seemingly, of little biological significance to their hosts ${ }^{93}$ - with Trichoderma appearing only infrequently. Only one study involved sampling of all the coffee tissues (leaf, berry, stem, root system) ${ }^{89}$ and, of the 843 isolates obtained, only four were identified as belonging to the genus Trichoderma. Conversely, and in sharp contrast, the Coffea samples from Africa in this study yielded 76 endophytic isolates of Trichoderma from the aerial plant tissues of a relatively small sample size, with a highly diverse taxonomic range, including four new species. At this stage, it is not possible to determine whether the new taxa described herein are geographically restricted to Africa or even to coffee. Nevertheless, we find it significant that a far richer diversity of Trichoderma was found in association with coffee in its African centre of origin compared to that elsewhere, especially in the Neotropics. We also find particularly relevant the complete absence of endophitic Trichoderma species isolates amongst the plethora of fungal isolates obtained from our sampling in semi-wild situations in Brazil. This was entirely unexpected and may indicate the existence of a 'Trichoderma void' in the coffee endophyte mycobiota outside of Africa.

The occurrence of Trichoderma in association with C. arabica has been reported previously in Ethiopia ${ }^{15,94}$, but these studies focused on strains isolated from the rhizosphere and root tissues. The isolates included: $T$. harzianum sensu lato, T. hamatum, T. asperelloides, T. spirale, T. atroviride, T. koningiopsis, T. gamsii and T. longibrachiatum. Only three of these taxa were isolated during our study of stems, leaves and berries: namely, $T$. hamatum, T. spirale and T. koningiopsis. These are cosmopolitan species that are frequently isolated from tropical habitats, especially from soil ${ }^{6,7,60,95}$. Certain Trichoderma species were isolated from more than one plant tissue type: T. koningiopsis and T. spirale from the leaves and stems of C. canephora; T. hamatum from the stems and berries of C. arabica. T. hamatum, T. koningiopsis and T. spirale have also been reported as endophytes in other tropical woody plants, notably cacao and rubber ${ }^{5}$. Nevertheless, only T. hamatum had previously been reported as endophytic in C. arabica; occurring in the root system ${ }^{15,94}$. Apart from the four novel species described here, other Trichoderma species were found for the first time as endophytes in coffee: T. atroviride, T. guizhouense, T. breve and T. theobromicola. These species were known from other habitats, such as: tropical soils; decaying wood and bark; as mycoparasites; on mushroom compost; in leaf-cutting ant colonies; and as endophytes in Theobroma spp. (Malvaceae $)^{4,5,20,96,97}$. Trichoderma guizhouense has a worldwide distribution, mainly in soil, and had only been reported previously as an endophyte in the endemic woody liana, Ancistrocladus korupensis, and in the stems of Cola trees in primary forest in south-west Cameroon ${ }^{4}$. Previously, T. theobromicola was known only from South America, and reported to be a common endophyte in sapwood of cacao ${ }^{4,22,79}$ whilst $T$. breve, a recently described species isolated from soil, was previously known only from northern China ${ }^{12}$. These two species are new geographical and host records for Africa, but this may simply reflect the poor sampling of Trichoderma in the region, particularly for endophytes. The results of the surveys also suggest that many species of Trichoderma are either cosmopolitan or pantropical.

Mycoparasitism - the ecological relationship where one fungus parasitizes another ${ }^{98}$ - has now been reported for a number of species of Trichoderma, notably: T. atroviride, T. hamatum, T. longibrachiatum, T. reesei and T. virens, and it has recently been established that mycoparasitism is an ancestral trait of the genus ${ }^{19,99}$ Mycoparasitic Trichoderma spp. have a wide range of hosts, including true fungi, such as Botrytis cinerea, Rhizoctonia solani, Alternaria alternata and Fusarium spp., as well as Oomycetes, such as Pythium ultimum $^{49,98}$. However, the species found as mycoparasites of $H$. vastatrix reported here-T. aggressivum, T. andinense, T. parareesei, T. petersenii and T. pseudopyramidale - are the first in the genus to be reported attacking the Hemileia rusts associated with coffee. Three of the species of Trichoderma obtained during the surveys are well-known mycoparasites, but were found here only growing as endophytes in coffee, namely: T. atroviride, T. hamatum and T. virens. Trichoderma pseudopyramidale may deserve special attention as a potential biocontrol agent of CLR, since it was the most common mycoparasitic species obtained from both Cameroon and Ethiopia (77.8\% of total mycoparasites). In Ethiopia this species was commonly associated with a purported new species of Hemileia (cf. H. coffeicola) on wild C. arabica in cloud forest (ca. $2000 \mathrm{~m}$ ). It was also frequently isolated as an endophyte from the leaves and stems of both semi-wild and wild C. arabica in Ethiopia (see Table 1). It may encompass dual roles as an endophytic bodyguard of coffee and also as a contact mycoparasite of CLR.

Mycoparasitic fungi associated with coffee rust have been studied $n$ regions of the world where coffee is not a native species, such as in Mexico ${ }^{100}$. It is interesting to note that this Mexican survey identified six purported mycoparasites: Acremonium byssoides, Calcarisporium ovalisporum, C. arbuscula, Fusarium pallidoroseum, Sporothrix guttuliformis and Verticillium (=Akanthomyces lecanii). A more recent publication reporting the results of an investigation in Mexico and Puerto Rico, involving the use of single-molecule DNA sequencing of fungal rRNA gene barcodes to identify putative mycoparasites in pustules of $H$. vastatrix, yielded 15 fungal taxa associated with CLR, none of which belonged to Trichoderma ${ }^{101}$. Information on the ecology of the new Trichoderma species described here, and their role in nature, is limited because relatively few strains of each species were isolated during the survey; the exceptions being T. botryosum and T. pseudopyramidale, which constituted over $60 \%$ of the total isolations and seem to have a close association with their Coffea hosts, in both Cameroon and Ethiopia, in wild, semi-wild and cultivated situations.

The aim of the present study was to collect and catalogue endophytes of Coffea species-as well as the mycoparasites of the associated Hemileia rusts-in their African centres of origin, as part of a project to screen and 
assess these isolates as potential biological control agents of CLR. The target area is Central America where the rust has become a critical constraint to coffee production, as well as causing a socio-economic crisis, over the past decade ${ }^{53,102,103}$. The work presented here covers only the taxonomy with some observations on the ecology of the Trichoderma isolates resulting from the surveys in Africa, but these data will be pivotal for selecting candidate biocontrol agents for the potential management of $H$. vastatrix in the Americas.

The philosophy behind the overall project is based on the concepts of classical biological control and, in the case of CLR, on the Enemy Release Hypothesis which posits that exotic species become invasive and achieve pest status because of increased fitness in the absence of their coevolved natural enemies ${ }^{104}$. One solution to address the problem of invasive alien pests is to source, import and release coevolved natural enemies from the centres or regions of origin of the target species in order to reduce 'pest' fitness: the classical biological control strategy. This approach using fungal natural enemies, such as entomopathogens and plant pathogens, has been employed successfully to control invasive alien arthropod pests and weeds ${ }^{105,106}$, but never against alien plant diseases using mycoparasites. The evidence from our study indicates that there is a guild of Trichoderma species, potentially antagonistic to $H$. vastatrix in Africa, which could be exploited for biological control of CLR in Central America following the classical approach. There are claims that non-specific, indigenous mycoparasites; notably, Lecanicillium lecanii-now Akanthomyces lecanii ${ }^{107}$ - can reduce the impact of CLR in the Americas ${ }^{108}$, but this is not evident based on the continuing rust outbreaks.

Another scenario has been suggested to further explain the invasiveness of alien plant species: the EndophyteEnemy Release Hypothesis ${ }^{109}$, which posits that alien plants arrive not only without their coevolved natural enemies but also deficient in, or completely lacking, coevolved endophytes, some of which may be acting as symbionts ('bodyguards'); protecting their hosts against adverse abiotic and biotic factors. Thus, in their absence, exotic crops thrive and alien weeds invade, with no natural enemies reducing plant fitness and fecundity and no bodyguards to 'pay' for protection. In crop species, the consequences can be catastrophic when coevolved natural enemies-lacking their own natural enemies, such as mycoparasites (in the case of fungal pathogens)eventually catch up with their endophyte-deficient plant hosts. Such may be the case with H. vastatrix in Central America-and, of course, this may explain the devastating rust epiphytotics that destroyed coffee cultivation in Sri Lanka (Ceylon) in the nineteenth century, as well as in all the global regions where the rust has invaded ${ }^{110}$.

Thus, the ideal classical biological control agent for CLR would combine the best of both worlds in the form of an endophytic mycoparasite, and-as our results indicate-the genus Trichoderma contains such candidates. Potentially, these would not only be used to colonize the coffee leaf and parasitize the external rust pustulesas well as to target the invasive, intercellular mycelium of the rust-but also to bolster host defences through induced resistance $66,84,111$. There is increasing evidence that, in addition to induced resistance to diseases and pests, endophytic Trichoderma species confer a range of other benefits to their plant host, in particular, drought tolerance, resistance to abiotic factors such as salt stress and growth stimulation $5,21,23,27,28,30,32,36,43,71,72,81,85-87,112$.

Preliminary data, using Trichoderma isolates from the survey, are showing positive results in the laboratory with evidence of reduction in rust disease severity ${ }^{113}$ (Authors, unpublished). Greenhouse screening of four isolates of Trichoderma (COAD 2418, COAD 2417, COAD 2535 and COAD 2439), belonging to T. hamatum and T. pseudopyramidale sp. nov.., showed their ability to inhibit the germination of $H$. vastatrix urediniospores above $70 \%$ in vitro. Isolate COAD 2396 (T. atroviride) reduced the severity of the disease to less than $50 \%$ of the levels observed in the controls when applied before or simultaneously with $H$. vastatrix on coffee leaf discs. In addition, an isolate of T. parareesei (COAD 2482) promoted the growth and increased the biomass of tomato roots by $33 \%$ and $57 \%$, respectively; whilst others are now showing the ability to increase drought tolerance ${ }^{113}$ (Authors, unpublished).

The methodology employed during the survey for the isolation of endophytes has proven to be robust. It has been emphasized previously that endophyte isolation is a method-dependent process and this will determine the quality and quantity of fungi obtained ${ }^{114}$. In our experience, isolating in situ-directly in the field from tree stems-or immediately after collection, eliminates or reduces contamination by many of the opportunistic endophytes and favours the slower-growing, potentially obligate endophytes. This has consistently been demonstrated not only during the present coffee survey in Africa, but also from previous surveys of wild species of Theobroma and Hevea in South American rainforests where this approach was pioneered ${ }^{20,36,39}$ These surveys resulted not only in the discovery of numerous new Trichoderma taxa-which are still being described ${ }^{4,41}$ - but in many other taxonomic novelties, including new endophytic lineages of Tolypocladium and a new class of Pezizomycotina ${ }^{115,116}$. Moreover, they reveal the paucity of endophytes in cultivated exotic plants-in this instance, cacao and rubber-compared to wild populations of Theobroma and Hevea in natural ecosystems ${ }^{39,41,117-119}$. This has been confirmed during the present study, when a survey of coffee endophytes in four states of Brazil, failed to isolate any species of Trichoderma, providing compelling evidence that centres of origins or diversity of plants harbour unique guilds of endophytic Trichoderma species-as well as other genera-that could be exploited not only for classical biological control but also as potential reservoirs of novel metabolites.

In conclusion, our surveys in Africa for endophytes and mycoparasites associated with the genus Coffea and with its Hemileia rusts have revealed a highly diverse range of fungi, with many novel species; Trichoderma being just one component. Because of the relatively few countries (3) and localities (18) visited, and the restricted number of host plants sampled, this can only be viewed as a snapshot of the actual diversity of endophytes, as well as of mycoparasites, associated with Coffea in Africa, especially in forest ecosystems. Potentially, in Madagascar, where the diversity of the genus is richer with 59 confirmed species ${ }^{120}$, this still-untapped diversity could be even higher. Loss of forest habitats in Africa and Madagascar means that many of these fungi will go extinct, along with their host plants, before being described. The potential loss of such key antagonists of the CLR fungus-as well as of Coffea germplasm-should be cause for concern to coffee stakeholders. 


\section{Materials and methods}

Sampling and isolation. The fungal isolates were all obtained during survey collections in Africa, namely: Kenya (May-June, 2015); Cameroon (November, 2015); Ethiopia (November, 2015; May-June, 2017; January, 2018). In addition, surveys were made in coffee farms in Brazil to compare and contrast the guilds of Trichoderma present in the native and exotic ranges of coffee. Surveys were undertaken in cooperation with African scientists from local research organizations: notably, IRAD (Institut de Recherche Agricole pour le Developpement), in Cameroon; Jimma University and Ethiopian Institute of Agricultural Research, in Ethiopia. Ad hoc surveys were also undertaken by the local scientists. The surveys were targeted at areas where wild species of Coffea occur and, specifically, where the main species of commerce-Coffea arabica (Kenya and Ethiopia) and Coffea canephora (Cameroon-Congo Basin) - are present in the wild, or are cultivated in semi-wild conditions (Figs. 13a,b, 14a-c, 15a,b). At each selected site, Coffea plants were examined for rust pustules-with particular attention to collecting rust colonies exhibiting mycoparasitism, or appearing to be abnormal (unusual colour, poor sporulation) (Figs. 14d, 15c,d). Specimens were dried in a plant press for later processing in the laboratory (preliminary identification and isolation). Also, at each site, samples of at least three separate adult plants were collected, consisting of healthy leaves, berries and 3-cm diam or thicker stem sections of each individual, and bagged for examination and processing later the same day. Isolations were made from healthy leaves, stems and berries of C. arabica, C. brevipes, C. canephora and C. eugenioides (Figs. 13c-f, 15e). The isolation protocol followed the procedure described by Evans et al. ${ }^{20}$ with modifications, and were performed as described below.

1. Stems in situ were thoroughly rubbed with cotton wool soaked in $70 \%$ alcohol and, after the alcohol had evaporated, the bark was removed using a flamed knife or machete blade (Fig. 13a). The exposed panel was then cleaned with a scalpel (Swann Morton 10) and the surface further pared with a smaller blade (Swann Morton 11). Nine, triangular slivers of sapwood $(c a .8 \times 5 \mathrm{~mm})$ were excised with a scalpel (Swann Morton $10 \mathrm{~A}$ ) from the panel and transferred individually with fine forceps to three plastic Petri plates (3- or 5- $\mathrm{cm}$ diam; 3 samples/plate), containing selective media: potato dextrose agar (PDA), one-fifth strength (20\% PDA), supplemented with $10 \mathrm{mg} / \mathrm{l}$ penicillin-streptomycin solution. These were sealed immediately with electrical tape and stored in plastic boxes. During these procedures, all instruments were surface sterilized in $90 \%$ ethanol and flamed using a portable, alcohol burner. On arrival at the laboratory, the plates were transferred to a $25^{\circ} \mathrm{C}$ incubator and examined regularly over an 8 -week period. Hyphal tips or spores were excised or picked from colonies as they appeared on or around the wood samples and transferred to 5-cm diam, plastic Petri plates containing 20\% PDA or potato carrot agar (PCA) and incubated under black light at $25^{\circ} \mathrm{C}$ to promote sporulation. This procedure was firstly described for the isolation of endophytic fungi by Evans et al. ${ }^{20}$ but was applied here for the first time for endophytic fungi from coffee.

2. Young mature healthy leaves (third from the branch tip) were thoroughly rubbed with cotton wool soaked in $70 \%$ alcohol and, after the alcohol had evaporated, three small $(c a .5 \times 5 \mathrm{~mm})$ square fragments were excised from the leaf centre (including the midrib) and were surface sterilized for $3 \mathrm{~min}$ by immersion in $10 \%$ bleach, followed by immersion in sterile water in stoppered plastic tubes and, following a thorough agitation, were plated as described for stems. Subsequent processing was as described for stems.

3. Whenever available, Coffea berries were also sampled and treated similarly as described above for leaf samples but, after surface cleaning with alcohol, each fruit was skinned and inner parts were divided into three slices which were then surface sterilized before plating. Further steps followed the same procedure as described above.

For the isolation of mycoparasites, conidia from parasitized rust pustules were selected and picked-off with a sterile needle, using a dissecting microscope, and transferred to PDA plates. The dried samples were processed within 2 weeks of collection after transport to the laboratory in the UK or Brazil.

The same endophyte isolation protocol described above was utilized for samples collected at eight localities in four Brazilian states (Espírito Santo, Minas Gerais, São Paulo and Rio de Janeiro). Survey sites closest to those where coffee was sampled in Africa were selected; concentrating on those where coffee plants were growing in semi-wild or forest situations, such as abandoned coffee farms and invasive populations in Atlantic rainforest (Fig. 16).

DNA extraction, PCR amplification and sequencing. Strains were grown in 3-cm diam plates containing $5 \mathrm{~mL}$ of potato dextrose broth (PD) at $25^{\circ} \mathrm{C}$ in the dark for $4-5$ days. DNA was extracted from the mycelium grown on the surface of the broth. DNA was extracted with the Wizard Genomic DNA Purification kit (Promega, Madison, EUA) by following the manufacturer's instructions. The fragments $r p b 2$ (primers fRPB27cR-RPB25F2) ${ }^{121}$ and tef1 (primers EF2-EF1728M) were amplified for all isolates and additionally cal (primers CAL228-CAL737) ${ }^{122}$ was amplified for a subset of 12 isolates.

The polymerase chain reaction (PCR) amplifications were performed in a total reaction volume of $12.5 \mu \mathrm{l}$, including $0.25 \mu \mathrm{l}$ of each primer, $1.25 \mu \mathrm{l}$ of BSA, 6.25 of Taq polymerase [including dNTPs], $0.25 \mu \mathrm{l}$ of genomic DNA [30 ng/ $\mu \mathrm{l}$ ]; $0.25 \mu \mathrm{l} \mathrm{DMSO}$ and $4 \mu \mathrm{l}$ of sterile ultrapure water. PCR conditions for $r p b 2$ were $95^{\circ} \mathrm{C} / 5 \mathrm{~min}$., followed by 38 cycles at $95{ }^{\circ} \mathrm{C} / 1 \mathrm{~min}$., $58^{\circ} \mathrm{C} / 2 \mathrm{~min}$., $72{ }^{\circ} \mathrm{C} / 2 \mathrm{~min}$. and $72{ }^{\circ} \mathrm{C} / 10 \mathrm{~min}$. For tefl, conditions were $94^{\circ} \mathrm{C} / 2 \mathrm{~min}$., followed by 9 cycles at $94{ }^{\circ} \mathrm{C} / 35 \mathrm{~s}, 66^{\circ} \mathrm{C} / 55 \mathrm{~s}$, and 35 cycles at $94{ }^{\circ} \mathrm{C} / 35 \mathrm{~s}, 56^{\circ} \mathrm{C} / 55 \mathrm{~s}$ and $72^{\circ} \mathrm{C} / 1 \mathrm{~min} 30 \mathrm{~s}$. Conditions for cal were $95^{\circ} \mathrm{C} / 8 \mathrm{~min}$., followed by 35 cycles at $95{ }^{\circ} \mathrm{C} / 15 \mathrm{~s}, 55^{\circ} \mathrm{C} / 20 \mathrm{~s}$, $72{ }^{\circ} \mathrm{C} / 1 \mathrm{~min}$ and extension at $72^{\circ} \mathrm{C} / 5 \mathrm{~min}$. PCR products were visualized by Gelred (Thermo Fisher Scientific) staining following electrophoresis of $4 \mu \mathrm{l}$ of each product in $1 \%$ agarose gel. The PCR products were sequenced by Macrogen Inc., South Korea (http://www.macrogen.com). 

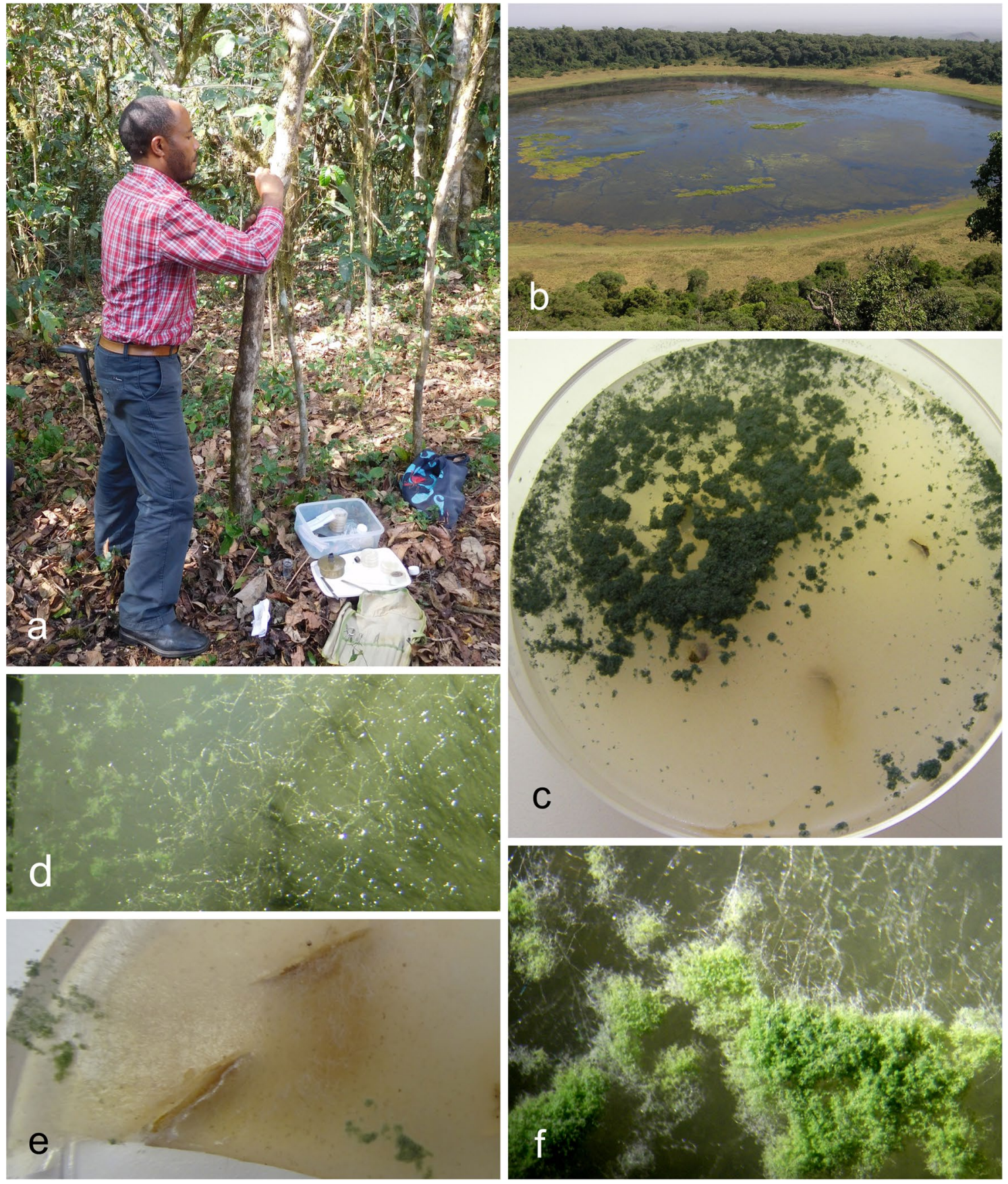

Figure 13. Survey protocol and isolates of Trichoderma. (a) Kifle Belachew isolating endophytes directly from main stem of Coffea arabica in a semi-wild coffee farm in the Kaffa Zone of Ethiopia. (b) Lake Paradise in Marsabit Forest Reserve, Eastern Province of Kenya where wild Coffea cf. arabica is common in the understorey. (c-f) Trichoderma isolates growing from Marsabit coffee stem samples, including Trichoderma lentissimum sp. nov. (e).

Phylogenetic analysis. Consensus sequences were assembled from forward and reverse sequencing chromatograms using SeqAssem ${ }^{123}$ tef1, rpb2 and cal contigs of all strains were compared to homologous sequences deposited in NCBI GenBank. Sequences generated in the present study were deposited in the NCBI GenBank database (Table 1) and sequences obtained in other studies were used in our phylogenetic analyses and were retrieved from the NCBI GenBank database (Supplementary Table S1) T. Sequence alignments were performed using MUSCLE implemented in MEGA $10^{124}$. In total, the dataset comprised 324 partial tef1 (sequences $664 \mathrm{pb}$ ); 169 partial $r p b 2$ sequences $(951 \mathrm{pb})$ and 25 partial cal sequences (443 pb). Two concatenated trees with tef1 and rpb2 sequences were created, one with taxa of the clades Harzianum (more numerous), Stricpile and Virens, and the other with the rest of the taxa (Figs. 1 and 2); a third concatenated analysis with partial sequences of three genes, tef, $r p b 2$ and $c a l$, was constructed with a subgroup of sequences to clarify thephylogenetic relationships of 

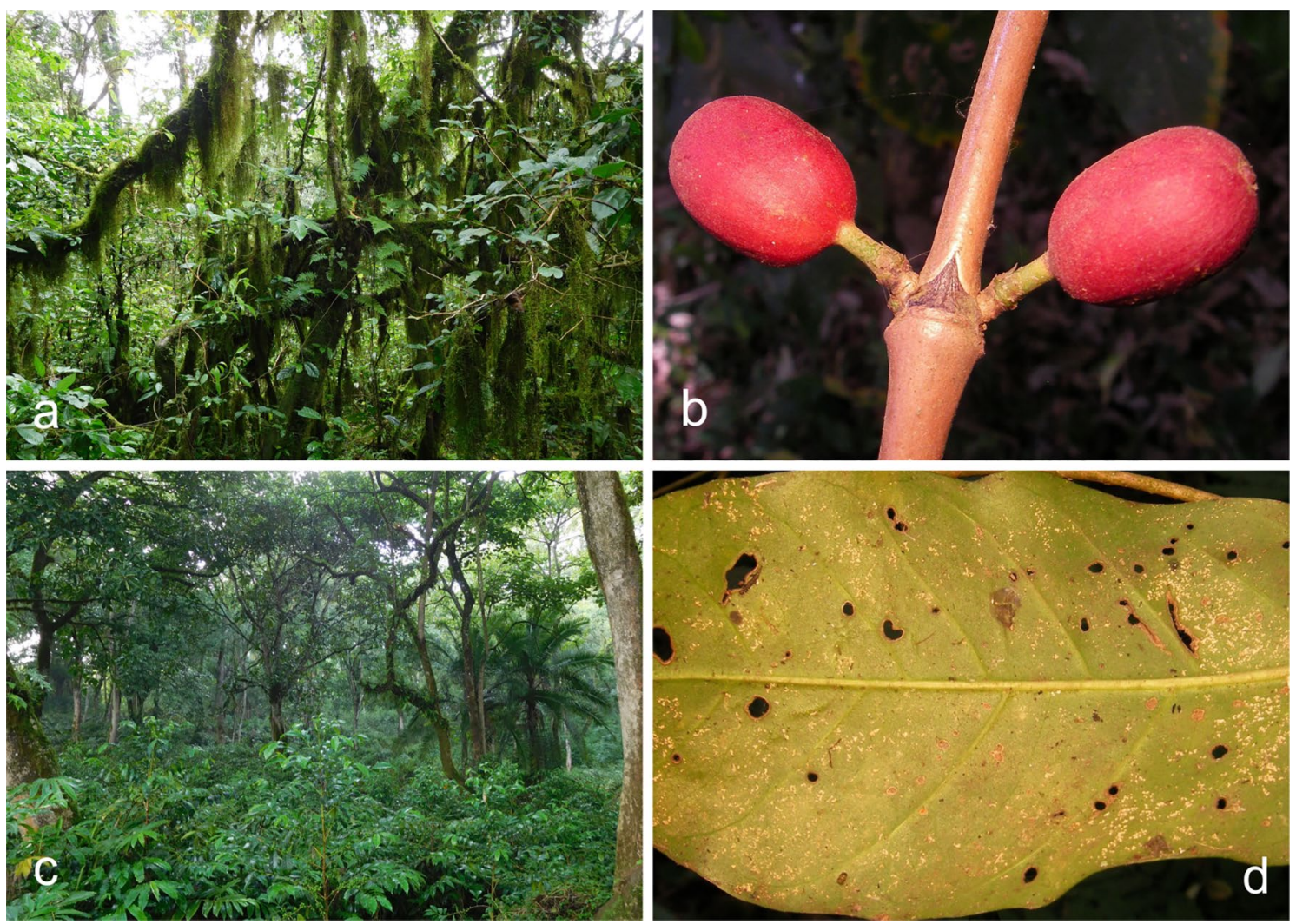

Figure 14. Survey in Ethiopia. (a) Komba Forest Reserve, Kaffa Zone, at ca. $2000 \mathrm{~m}$ altitude; showing wild Coffea arabica in the cloud forest understorey. (b) Wild Coffea arabica in Komba Forest Reserve with few, large berries at each node in contrast to the multiple, smaller berries of commercial varieties. (c) Typical semi-wild coffee farm of the Kaffa Zone, at ca. $1500 \mathrm{~m}$ altitude, established under thinned forest. (d) Leaf from the above wild coffee plant colonized by two rust species: the dominant white scattered pustules of Hemileia cf. coffeicola; and a typical orange dense pustule of $H$. vastatrix, an uncommon rust in cloud forest.

some species within the clade Harzianum (Fig. 3), such trees containing 168 taxa with 2515 characters, 86 taxa with 2422 characters and 25 taxa with 1927 characters, respectively. The concatenated alignments were generated in Sequence matrix v1.8 $8^{125}$. Single-gene trees were also generated. Maximum parsimony (MP), Maximum likelihood (ML) and Bayesian Inference (BI) were performed for the concatenated and single-gene trees. Prior to phylogenetic analyses, the most appropriate nucleotide substitution model for each locus was selected using MRMODELTEST v. $2^{126}$. Nucleotide substitution models in the two-gene concatenated trees were HKY $+\mathrm{I}+\mathrm{G}$ and $S Y M+I+G$ (Figs. 1 and 2), for tef1 and $r p b 2$, respectively. For the three-gene concatenated tree, the models were $\mathrm{HKY}+\mathrm{I}, \mathrm{K} 80+\mathrm{I}$ and $\mathrm{K} 80+\mathrm{G}$ (Fig. 3) for tef, $r p b 2$ and cal, respectively. For all trees the BI and ML analysis were estimated in the CIPRES Science Gateway Platform using Mr. Bayes 3.2.6 and RaxML-HPC v.8, respectively ${ }^{127,128}$ and MP in MEGA 10. Phylogenetic trees were visualized using FigTree (http://tree.bio.ed.ac. $\mathrm{uk} /$ software/figtree/). Phylogenetic species were recognized based on two main previously accepted criteria ${ }^{129}$ Genealogical Concordance (the clade was present in the majority of the single-locus genealogies, as revealed by a majority-rule consensus tree) and Genealogical Non-discordance (the clade was well supported in the least one single-locus genealogy, as judged both by MP and BI and was not contradicted in any other single-locus genealogy at the same level of support).

Morphological characteristics. The results of the phylogenetic analysis of the assemblage of Trichoderma isolates guided the selection of isolates to be included in the morphological analysis and characterization of novel taxa. One or two isolates of each new taxon were examined. Procedures for morphological observation of Trichoderma followed the protocol established by Samuels and Hebbar ${ }^{5}$. Macroscopic characteristics of colonies-mycelium colour, radial growth, presence/absence of concentric rings, sporulation "pustules" ${ }^{2}$, pigmentation and presence/absence of odour-were evaluated on PDA, CMD (Corn-meal Agar) and SNA (Synthetic Nutrient Deficient Agar) after 7 days at $25^{\circ} \mathrm{C}$ under a 12-h daily light regime (light provided by two white and one near-UV lamps placed $35 \mathrm{~cm}$ above the plates). Rates of growth were evaluated at 72 and $96 \mathrm{~h}$ on the three culture media at 25,30 and $35^{\circ} \mathrm{C}$ in the dark. Observations of fungal structures were made using an Olympus BX 51 microscope and were based on slide cultures prepared with colonies of each isolate growing from PDA and CMD blocks ${ }^{130}$. After $4-5$ days of growth at $25^{\circ} \mathrm{C}$ under the same light regime described above, the slides were mounted in $3 \% \mathrm{KOH}$ for observation and illustration. Descriptions included biometric data of phialides, conidia and chlamydospores. Measurements were taken from images generated with a digital camera Olympus Q-Color 3. 

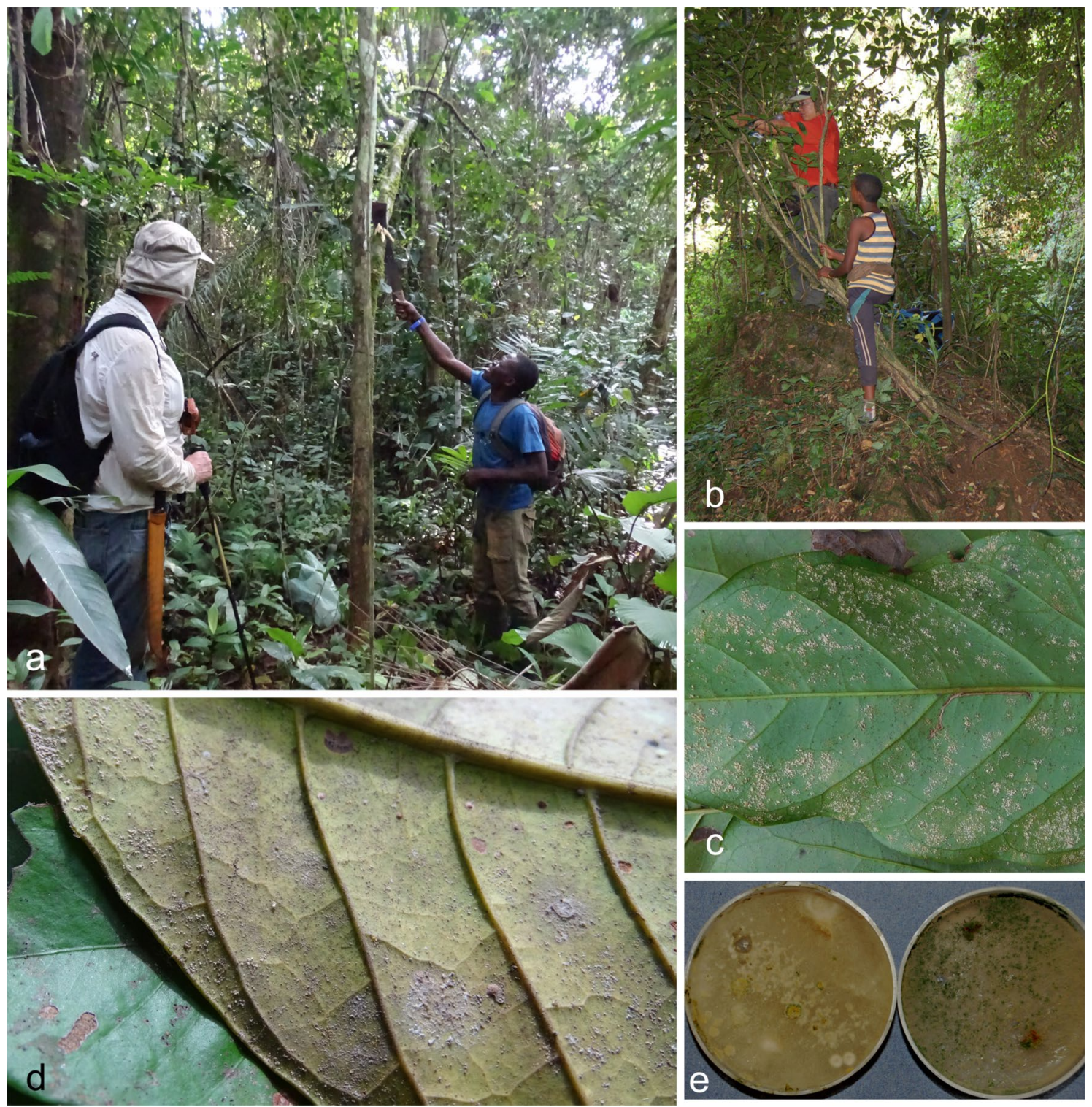

Figure 15. Survey sites and rust collections. (a) Wild Coffea canephora tree (>10 m high) in understorey of Dja Forest Reserve, Eastern Province, Cameroon, ca. $700 \mathrm{~m}$ altitude; stem samples from this tree yielded four Trichoderma spp. (b) Collecting samples from wild Coffea arabica at Natural Bridge, Makira-Grugguto, Kaffa Zone, Ethiopia, ca. $1600 \mathrm{~m}$ altitude; Trichoderma pseudopyramidale sp. nov. was isolated from the leaves and stem of this tree. (c) Hemileia coffeicola on leaf of Coffea canephora, Somalomo Town, Eastern Province, Cameroon; showing the white to pale yellow, loose and scattered pustules. (d) Hemileia coffeicola completely parasitized by a guild of mycoparasites, including Trichoderma pseudopyramidale sp. nov., in a coffee plantation near Somalomo Town; imparting a grey appearance to the rust infection. (e) Two plates showing predomination of Trichoderma colonies emerging from field samples.

Statement. All experimental protocols adopted during this research were approved by the Comissão de Pesquisa do Departamento de Fitopatologia-Universidade Federal de Viçosa.

Informed consent. Informed consent was obtained to publish the names/information/images of all study participants appearing in the publication.

Ethical approval. All experimental protocols were approved by a named institutional and/or licensing committee/s. All methods were carried out in accordance with relevant guidelines and regulations. 

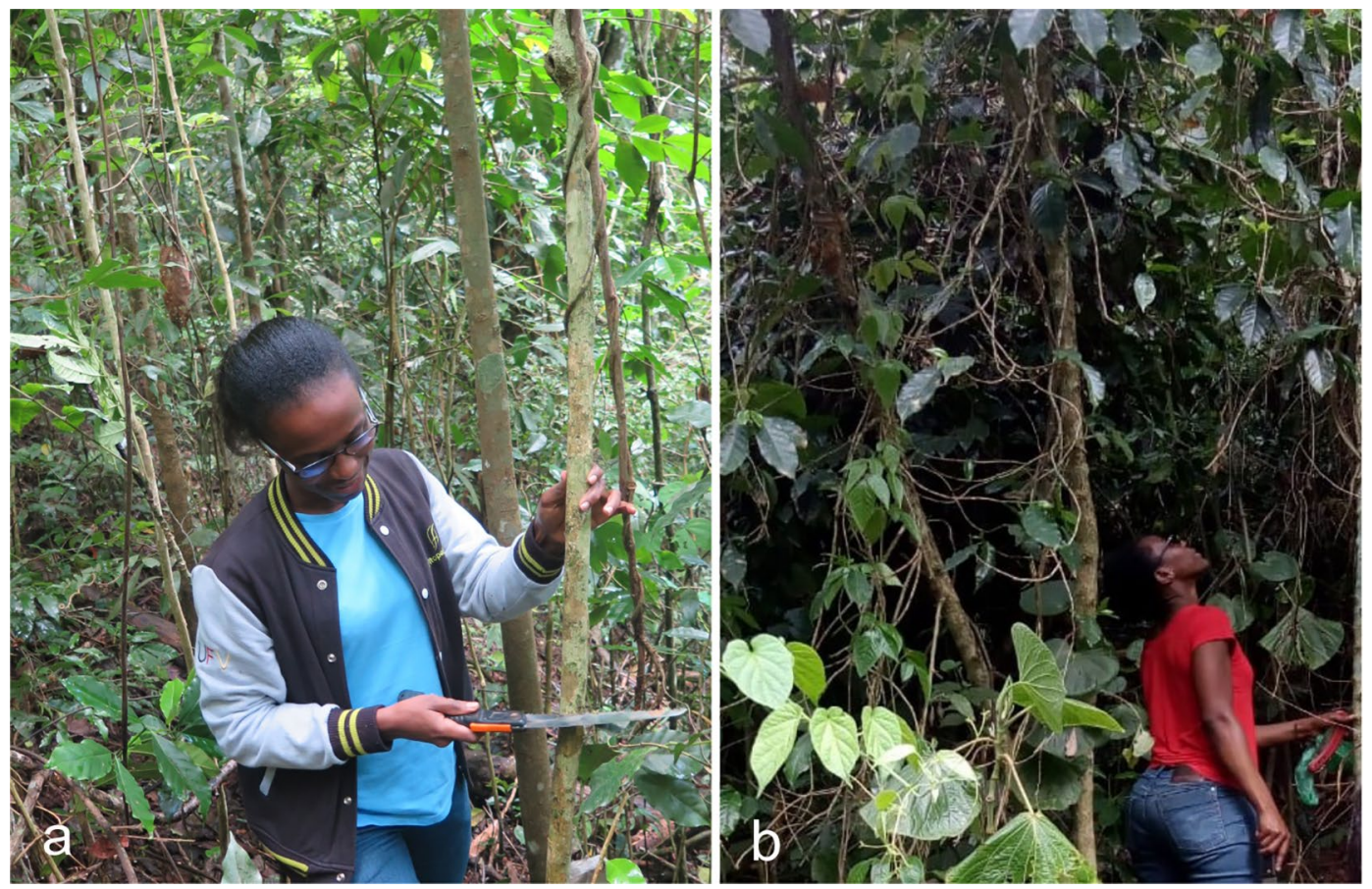

Figure 16. Survey sites in semi-wild situations in Brazil. (a) Miraine Ndacnou collecting a sample of mature Coffea arabica from the forest reserve Mata do Paraíso (Universidade Federal de Viçosa, state of Minas Gerais, Brazil). Notice the well-established secondary forest (Mata Atlântica) under which the coffee plants exist. (b) Miraine Ndacnou selecting a mature Coffea arabica growing in a forest fragment (Mata Atlântica) of the Fazenda Camocim (Pedra Azul, Domingos Martins, state of Espírito Santo, Brazil) for sampling.

Received: 18 May 2020; Accepted: 4 February 2021

Published online: 11 March 2021

\section{References}

1. Jiang, Y. et al. Trichoderma biodiversity of agricultural fields in east China reveals a gradient distribution of species. PLoS ONE 11, e0160613. https://doi.org/10.1371/journal.pone.0160613 (2016).

2. Jaklitsch, W. M. \& Voglmayr, H. New combinations in Trichoderma (Hypocreaceae, Hypocreales). Mycotaxon 126, 143-156. https://doi.org/10.5248/126.143 (2014).

3. Jaklitsch, W. M. \& Voglmayr, H. Biodiversity of Trichoderma (Hypocreaceae) in Southern Europe and Macronesia. Stud. Mycol. 80, 1-87. https://doi.org/10.1016/j.simyco.2014.11.001 (2015).

4. Chaverri, P. et al. Systematics of the Trichoderma harzianum species complex and the re-identification of commercial biocontrol strains. Mycologia 107, 558-590. https://doi.org/10.3852/14-147 (2015).

5. Samuels, G. J. \& Hebbar, P. K. Trichoderma: Identification and Agricultural Applications (APS Press, St. Paul, 2015).

6. Kubicek, C. P., Bissett, J., Druzhinina, I. S., Kullnig-gradinger, C. \& Szakacs, G. Genetic and metabolic diversity of Trichoderma: A case study on South-East Asian isolates. Fungal Genet. Biol. 38, 310-319. https://doi.org/10.1016/s1087-1845(02)00583-2 (2003).

7. Hoyos-Carvajal, L., Orduz, S. \& Bissett, J. Genetic and metabolic biodiversity of Trichoderma from Colombia and adjacent neotropic regions. Fungal Genet. Biol. 46, 615-631. https://doi.org/10.1016/j.fgb.2009.04.006 (2009).

8. Chaverri, P., Samuels, G. J. \& Gazis, R. O. Trichoderma amazonicum, a new endophytic species on Hevea brasiliensis and $H$. guianensis from the Amazon basin. Mycologia 103, 139-151. https://doi.org/10.3852/10-078 (2011).

9. Jaklitsch, W. M. European species of Hypocrea Part II: Species with hyaline ascospores. Fungal Divers. 48, 1-250. https://doi. org/10.1007/s13225-011-0088-y (2011).

10. Qin, W. \& Zhuang, W. Seven wood-inhabiting new species of the genus Trichoderma (Fungi, Ascomycota) in Viride clade. Sci. Rep. 6, 1-14. https://doi.org/10.1038/srep27074 (2016).

11. Chen, K. A. I. \& Zhuang, W. Seven soil-inhabiting new species of the genus Trichoderma in the Viride clade. Phytotaxa 312, 28-46. https://doi.org/10.1038/srep27074 (2017).

12. Chen, K. \& Zhuang, W. Discovery from a large-scaled survey of Trichoderma in soil of China. Sci. Rep. 7, 1-37. https://doi. org/10.1038/s41598-017-07807-3 (2017).

13. Inglis, P. W. et al. Trichoderma from Brazilian garlic and onion crop soils and description of two new species : Trichoderma azevedoi and Trichoderma peberdyi. PLoS ONE 15, e0228485. https://doi.org/10.1371/journal.pone.0228485 (2020).

14. du Plessis, I., Druzhinina, I. S., Atanasova, L., Yarden, O. \& Jacobs, K. The diversity of Trichoderma species from soil in South Africa with five new additions. Mycologia 110, 559-583. https://doi.org/10.1080/00275514.2018 (2018).

15. Mulaw, T. B., Kubicek, C. P. \& Druzhinina, I. S. The rhizosphere of Coffea arabica in its native highland forests of Ethiopia provides a niche for a distinguished diversity of Trichoderma. Diversity 2, 527-549. https://doi.org/10.3390/d2040527 (2010).

16. Cox, P., Wilkinson, S. P. \& Anderson, J. M. Effects of fungal inocula on the decomposition of lignin and structural polysaccharides in Pinus sylvestris litter. Biol. Fertility Soils 33, 246-251. https://doi.org/10.1007/s003740000315 (2001).

17. Druzhinina, I. S., Kopchinskiy, A. L. G. \& Kubicek, C. P. The first 100 Trichoderma species characterized by molecular data. Mycoscience 47, 55-64. https://doi.org/10.1007/S10267-006-0279-7 (2006). 
18. Harman, G. E., Howell, C. R., Viterbo, A., Chet, I. \& Lorito, M. Trichoderma species-opportunistic, avirulent plant symbionts. Nat. Rev. 2, 43-56. https://doi.org/10.1038/nrmicro797 (2004).

19. Mukherjee, P. K., Horwitz, B. A., Herrera-Estrella, A., Schmoll, M. \& Kenerley, C. M. Trichoderma research in the genome era. Annu. Rev. Phytopathol. 51, 105-129. https://doi.org/10.1146/annurev-phyto-082712-102353 (2013).

20. Evans, H. C., Holmes, K. A. \& Thomas, S. E. Endophytes and mycoparasites associated with an indigenous forest tree, Theobroma gileri, in Ecuador and a preliminary assessment of their potential as biocontrol agents of cocoa diseases. Mycol. Prog. 2, 149-160. https://doi.org/10.1007/s11557-006-0053-4 (2003).

21. Howell, C. R. Mechanisms employed by Trichoderma species in the biological control of plant diseases: The history and evolution of current concepts. Plant Dis. 87, 4-10. https://doi.org/10.1094/PDIS.2003.87.1.4 (2003).

22. Samuels, G. J. et al. Trichoderma theobromicola and T. paucisporum: Two new species isolated from cacao in South America. Mycol. Res. 110, 381-392. https://doi.org/10.1016/j.mycres.2006.01.009 (2006).

23. Bailey, B. A. \& Melnick, R. L. The endophytic Trichoderma. In Trichoderma: Biology and Applications 1st edn (eds Mukherjee, P. K. et al.) 152-172 (CAB International, Wallingford, 2013).

24. Chaverri, P. \& Samuels, G. J. Evolution of habitat preference and nutrition mode in a cosmopolitan fungal genus with evidence of interkingdom host jumps and major shifts in ecology. Evolution 7, 2823-2837. https://doi.org/10.1111/evo.12169 (2013).

25. Vinale, F. et al. A novel role for Trichoderma secondary metabolites in the interactions with plants. Physiol. Mol. Plant Pathol. 72, 80-86. https://doi.org/10.1016/j.pmpp.2008.05.005 (2008).

26. Lorito, M., Woo, S. L., Harman, G. E. \& Monte, E. Translational research on Trichoderma : From 'Omics to the field. Annu. Rev. Phytopathol. 48, 1-23. https://doi.org/10.1146/annurev-phyto-073009-114314 (2010).

27. Shoresh, M., Harman, G. E. \& Mastouri, F. Induced systemic resistance and plant responses to fungal biocontrol agents. Annu. Rev. Phytopathol. 48, 21-43. https://doi.org/10.1146/annurev-phyto-073009-114450 (2010).

28. Hermosa, R., Viterbo, A., Chet, I. \& Monte, E. Plant-beneficial effects of Trichoderma and of its genes. Microbiology 158, 17-25. https://doi.org/10.1099/mic.0.052274-0 (2012).

29. Mastouri, F., Björkman, T. \& Harman, G. E. Trichoderma harzianum enhances antioxidant defense of tomato seedlings and resistance to water deficit. Mol. Plant-Microbe Interact. 25, 1264-1271. https://doi.org/10.1094/MPMI-09-11-0240 (2012).

30. Harman, G. E., Doni, F., Khadka, R. B. \& Uphoff, N. Endophytic strains of Trichoderma increase the plants photosynthetic capability. J. Appl. Microbiol. https://doi.org/10.1111/jam.14368 (2019) (PMID: 31271695).

31. Hyde, K. D. et al. The amazing potential of fungi: 50 ways we can exploit fungi industrially. Fungal Divers. 97, 1-136. https:// doi.org/10.1007/s13225-019-00430-9 (2019).

32. Ikram, M. et al. Trichoderma reesei improved the nutrition status of wheat crop under salt stress. J. Plant Interact. 14, 590-602. https://doi.org/10.1080/17429145.2019.1684582 (2019).

33. Kiarie, S., Nyasani, J. O., Gohole, L. S., Maniania, N. K. \& Subramanian, S. Impact of fungal endophytes on induced resistance to thrips- and aphid-transmitted viruses. Plants 6, 416. https://doi.org/10.3390/plants9040416 (2020).

34. Samuels, G. J. et al. Trichoderma stromaticum sp. nov., a parasite of the cacao witches' broom pathogen. Mycol. Res. 104, 760-764. https://doi.org/10.1017/S0953756299001938 (2000).

35. Holmes, K. A., Schroers, H., Thomas, S. E., Evans, H. C. \& Samuels, G. J. Taxonomy and biocontrol potential of a new species of Trichoderma from the Amazon basin of South America. Mycol. Prog. 3, 199-210. https://doi.org/10.1007/s11557-006-0090-z (2004).

36. Samuels, G. J. Trichoderma: Systematics, the sexual state, and ecology. Phytopathology 96, 195-206. https://doi.org/10.1094/ PHYTO-96-0195 (2006).

37. Hanada, R. E. et al. Trichoderma martiale sp. nov., a new endophyte from sapwood of Theobroma cacao with a potential for biological control. Mycol. Res. 112, 1335-1343. https://doi.org/10.1016/j.mycres.2008.06.022 (2008).

38. Samuels, G. J. \& Ismaiel, A. Trichoderma evansii and T. lieckfeldtiae two new T. hamatum-like species. Mycologia 101, 142-156. https://doi.org/10.3852/08-161 (2009)

39. Gazis, R. \& Chaverri, P. Diversity of fungal endophytes in leaves and stems of wild rubber trees (Hevea brasiliensis) in Peru. Fungal Ecol. 3, 240-254. https://doi.org/10.1016/j.funeco.2009.12.001 (2010).

40. Gazis, R. \& Chaverri, P. Wild trees in the Amazon basin harbor a great diversity of beneficial endosymbiotic fungi: Is this evidence of protective mutualism?. Fungal Ecol. 17, 18-29. https://doi.org/10.1016/j.funeco.2015.04.001 (2015).

41. Vaz, A. B. M. et al. A multiscale study of fungal endophyte communities of the foliar endosphere of native rubber trees in eastern Amazonia. Sci. Rep. 8, 16151. https://doi.org/10.1038/s41598-018-34619-w (2018).

42. Kubicek, C. P. \& Harman, G. E. Trichoderma and Gliocladium. Basic Biology, Taxonomy and Genetics 8th edn. (Taylor \& Francis, London, 1998).

43. Schuster, A. \& Schmoll, M. Biology and technology of Trichoderma. Appl. Microbiol. Biotechnol. 87, 787-799. https://doi. org/10.1016/C2012-0-00434-6 (2010).

44. Souza, J. T. et al. Genetic and biological diversity of Trichoderma stromaticum, a mycoparasite of the cacao witches' broom pathogen. Popul. Biol. 96, 61-67. https://doi.org/10.1094/PHYTO-96-0061 (2006).

45. Samuels, G. J., Ismaiel, A., de Souza, J. \& Chaverri, P. Trichoderma stromaticum and its overseas relatives. Mycol. Prog. 11, 215-254. https://doi.org/10.1007/s11557-011-0743-4 (2012).

46. Bettiol, W. et al. Produtos comerciais à base de agentes de biocontrole de doenças de plantas Vol. 88, 1-156 (Embrapa Meio Ambiente (Document), Jaguariuna, 2012).

47. Medeiros, F. H. V. et al. A novel, integrated method for management of witches' broom disease of cacao in Bahia, Brazil. Crop Prot. 29, 704-711. https://doi.org/10.1016/j.cropro.2010.02.006 (2010).

48. Elad, Y., Barak, R. \& Chet, I. Parasitism of sclerotia of Sclerotium rolfsii by Trichoderma harzianum. Soil Biol. Biochem. 16, 381-386. https://doi.org/10.1016/0038-0717(84)90037-3 (1984).

49. Druzhinina, I. S. et al. Trichoderma: The genomics of opportunistic success. Nat. Rev. 9, 749-759. https://doi.org/10.1038/nrmic ro2637 (2011).

50. Whipps, J. M. \& Lumsden, R. D. Commercial use of fungi as plant disease biological control agents: Status and prospects. In Fungi as Biocontrol Agents: Progress, Problems and Potential Vol. 9-22 (eds Butt, T. M. et al.) (CAB International, Wallingford, 2001).

51. Atanasova, L., Druzhinina, I. S. \& Jaklitsch, W. M. Two hundred Trichoderma species recognized based on molecular phylogeny. In Trichoderma: Biology and Applications Vol. 1 (eds Mukherjee, P. K. et al.) 10-42 (CAB International, Wallingford, 2013).

52. Bissett, J., Gams, W., Jaklitsch, W. \& Samuels, G. J. Accepted Trichoderma names in the year 2015. IMA Fungus 6, 263-295. https ://doi.org/10.5598/imafungus.2015.06.02.02 (2015).

53. Avelino, J. et al. The coffee rust crises in Colombia and Central America (2008-2013): impacts, plausible causes and proposed solutions. Food Sec. 7, 303-321. https://doi.org/10.1007/s12571-015-0446-9 (2015).

54. Githae, E. W., Gachene, C. K. K. \& Odee, D. W. Implications for in situ conservation of indigenous species with special reference to Coffea arabica L. populations in Mount Marsabit forest, Kenya. Trop. Subtrop. Agroecosyst. 14, 715-722 (2011).

55. Li, Q. R. et al. A novel Trichoderma species isolated from soil in Guizhou, T. guizhouense. Mycol. Prog. 12, 167-172. https://doi. org/10.1007/s11557-012-0821-2 (2012).

56. Samuels, G. J., Dodd, S. L., Gams, W., Castlebury, L. A. \& Petrini, O. Trichoderma species associated with the green mold epidemic of commercially grown Agaricus bisporus. Mycologia 94, 146-170. https://doi.org/10.2307/3761854 (2002). 
57. Arx, J. A. Plant pathogenic fungi. Nova Hedw. Beih. 87, 1-288 (1987).

58. Bissett, J. A revision of the genus Trichoderma. 11. Infrageneric classification. Can. J. Bot. 69, 2357-2372. https://doi.org/10.1139/ b91-297 (1991).

59. Atanasova, L., Jaklitsch, W. M., Komoń-Zelazowska, M., Kubicek, C. P. \& Druzhinina, I. S. Clonal species Trichoderma parareesei sp. nov. likely resembles the ancestor of the cellulase producer Hypocrea jecorina/T. reesei. Appl. Environ. Microbiol. 76, 7259-7267. https://doi.org/10.1128/AEM.01184-10 (2010).

60. Samuels, G. J. et al. The Trichoderma koningii aggregate species. Stud. Mycol. 56, 67-133. https://doi.org/10.3114/sim.2006.56.03 (2006).

61. Bainier, G. Mycothèque de l'École de Pharmacie. III, IV. Bull. Soc. Mycol. Fr. 22, 130-137 (1906)

62. Bissett, J. A revision of the genus Trichoderma. I. Section Longibrachiatum sec. nov. Can. J. Bot. 62, 924-931. https://doi. org $/ 10.1139 / \mathrm{b} 84-131(1984)$.

63. Krupke, O. A., Castle, A. J. \& Rinker, D. L. The North American mushroom competitor, Trichoderma f. aggressivum, produces antifungal compounds in mushroom compost that inhibit mycelial growth of the commercial mushroom Agaricus bisporus. Mycol. Res. 107, 1467-1475. https://doi.org/10.1017/S0953756203008621 (2003).

64. Samuels, G. J. et al. The Longibrachiatum clade of Trichoderma: A revision with new species. Fungal Divers. 55, 77-108. https ://doi.org/10.1007/s13225-012-0152-2 (2012).

65. Samuels, G., Petrini, O., Kuhls, K., Lieckfeldt, E. \& Kubicek, C. P. The Hypocrea schweinitzii complex and Trichoderma sect, Longibrachiatum. Stud. Mycol. 41, 1-54 (1998).

66. Coppola, M. et al. Trichoderma atroviride P1 colonization of tomato plants enhances both direct and indirect defense barriers against insects. Front. Physiol. 10, 813. https://doi.org/10.3389/fphys.2019.00813 (2019).

67. Marra, R. et al. Study of the three-way interaction between Trichoderma atroviride, plant and fungal pathogens by using a proteomic approach. Curr. Genet. 50, 307-321. https://doi.org/10.1007/s00294-006-0091-0 (2006).

68. Park, M. S., Bae, K. S. \& Yu, S. H. Two new species of Trichoderma associated with green mold of oyster mushroom cultivation in Korea. Mycobiology 34, 111-113 (2006).

69. Wang, C. \& Zhuang, W.-Y. Evaluating effective Trichoderma isolates for biocontrol of Rhizoctonia solani causing root rot of Vigna unguiculata. J. Integr. Agric. 18, 2072-2079. https://doi.org/10.1016/S2095-3119(19)62593-1 (2019).

70. Mabberley, D. J. The Plant-Book 2nd edn. (Cambridge University Press, Cambridge, 1998).

71. Studholme, D. J. et al. Investigating the beneficial traits of Trichoderma hamatum GD12 for sustainable agriculture insights from genomics. Front. Plant Sci. 4, 258-270. https://doi.org/10.3389/fpls.2013.00258 (2013).

72. Bae, H. et al. The beneficial endophyte Trichoderma hamatum isolate DIS $219 \mathrm{~b}$ promotes growth and delays the onset of the drought response in Theobroma cacao. J. Exp. Bot. 60, 3279-3295. https://doi.org/10.1093/jxb/erp165 (2009).

73. López-Quintero, C. A. et al. DNA barcoding survey of Trichoderma diversity in soil and litter of the Colombian lowland Amazonian rainforest reveals Trichoderma strigosellum sp. nov. and other species. Antonie Van Leeuwenhoek 104, 657-674. https:// doi.org/10.1007/s10482-013-9975-4 (2013).

74. Rocha, S. L. et al. Recognition of endophytic Trichoderma species by leaf-cutting ants and their potential in a Trojan-horse management strategy. R. Soc. open sci. 4, 160628. https://doi.org/10.1098/rsos.160628 (2017).

75. Bailey, B. A., Strem, M. D. \& Wood, D. Trichoderma species form endophytic associations within Theobroma cacao trichomes. Mycol. Res. 113, 1365-1373 (2009).

76. Leylaie, S. \& Zafari, D. Antiproliferative and antimicrobial activities of secondary metabolites and phylogenetic study of endophytic Trichoderma species from Vinca. Plants Front. Microbiol. 9, 1484. https://doi.org/10.3389/fmicb.2018.01484 (2018).

77. Jaklitsch, W. M., Samuels, G. J., Dodd, S. L., Lu, B. \& Druzhinina, I. S. Hypocrea rufa/Trichoderma viride: A reassessment, and description of five closely related species with and without warted conidia. Stud. Mycol. 55, 135-177. https://doi.org/10.3114/ sim.2006 (2006).

78. Druzhinina, I. S., Komon-Zelazowska, M., Atanasova, L., Seidl, V. \& Kubicek, C. P. Evolution and ecophysiology of the industrial producer Hypocrea jecorina (anamorph Trichoderma reesei) and a new sympatric agamospecies related to it. PLoS ONE 5, e9191. https://doi.org/10.1371/journal.pone.0009191 (2010).

79. Almeida, K. A., Armesto, C., Monteiro, F. P. \& de Souza, J. T. Diversity of Trichoderma species isolated from dead branches and sapwood of Theobroma cacao trees. Trop. Plant Pathol. 43, 90-94. https://doi.org/10.1007/s40858-017-0191-z (2018).

80. Seidl, V. \& Seiboth, B. Trichoderma reesei: Genetic strategies to improving strain efficiency. Biofuels 1, 343-354. https://doi. org/10.4155/bfs.10.1 (2010).

81. Rubio, M. B. et al. Identifying beneficial qualities of Trichoderma parareesei for plants. Appl. Environ. Microbiol. 80, $1864-1873$. https://doi.org/10.1128/AEM.03375-13 (2014).

82. Chaverri, P., Castlebury, L. A., Overton, B. E. \& Samuels, G. J. Hypocreal Trichoderma: Species with conidiophore elongations and green conidia. Mycologia 95, 1100-1140. https://doi.org/10.2307/3761915 (2003).

83. Oh, S.-Y., Park, M. S., Cho, H. J. \& Lim, Y. W. Diversity and effect of Trichoderma isolated from the roots of Pinus densiflora within the fairy ring of pine mushroom (Tricholoma matsutake). PLoS ONE 13, e0205900. https://doi.org/10.1371/journal.pone.02059 00 (2018).

84. Bae, H. et al. Endophytic Trichoderma isolates from tropical environments delay disease onset and induce resistance against Phytophthora capsici in hot pepper using multiple mechanisms. Mol. Plant-Microbe Interact. 24, 336-351. https://doi.org/10.1094/ MPMI-09-10-0221 (2011).

85. Romão-Dumaresq, A. S. et al. Diversity of cultivated fungi associated with conventional and transgenic sugarcane and the interaction between endophytic Trichoderma virens and the host plant. PLOS ONE 11, e0158974. https://doi.org/10.1371/journ al.pone.0158974 (2016).

86. Nogueira-Lopez, G. et al. The apoplastic secretome of Trichoderma virens during interaction with maize roots shows an inhibition of plant defence and scavenging oxidative stress secreted proteins. Front. Plant Sci. 9, 409. https://doi.org/10.3389/fpls.2018.00409 (2018).

87. Contreras-Cornejo, H. A., Macías-Rodríguez, L., Cortés-Penagos, C. \& López-Bucio, J. Trichoderma virens, a plant beneficial fungus, enhances biomass production and promotes lateral root growth through an auxin-dependent mechanism in Arabidopsis. Plant Physiol. 149, 1579-1592. https://doi.org/10.1104/pp.108.130369 (2009).

88. Santamaría, J. \& Bayman, P. Fungal epiphytes and endophytes of coffee leaves (Coffea arabica). Microbial Ecol. 50, 1-8. https:// doi.org/10.1007/s00248-004-0002-1 (2005).

89. Vega, F. E. et al. Fungal endophyte diversity in coffee plants from Colombia, Hawaii, Mexico and Puerto Rico. Fungal Ecol. 3, 122-138. https://doi.org/10.1016/j.funeco.2009.07.002 (2010)

90. Oliveira, M. N. V. et al. Endophytic microbial diversity in coffee cherries of Coffea arabica from Southeastern Brazil. Can. J. Microbiol. 59, 221-230. https://doi.org/10.1139/cjm-2012-0674 (2013).

91. Oliveira, R. J. V., Souza, R. G., Lima, T. E. F. \& Cavalcanti, M. A. Q. Endophytic fungal diversity in coffee leaves (Coffea arabica) cultivated using organic and conventional crop management systems. Mycosphere 5, 523-530. https://doi.org/10.5943/mycos phere/5/4/4 (2014).

92. Saucedo-García, A., Anaya, A. L., Espinosa-García, F. J. \& González, M. C. Diversity and communities of foliar endophytic fungi from different agroecosystems of Coffea arabica L. in two regions of Veracruz, Mexico. PLoS ONE 9, e98454. https://doi. org/10.1371/journal.pone.0098454 (2014). 
93. Schulz, B. \& Boyle, C. The endophytic continuum. Mycol. Res. 109, 661-686. https://doi.org/10.1017/S095375620500273X (2005).

94. Mulaw, T. B., Druzhinina, I. S., Kubicek, C. P. \& Atanasova, L. Novel endophytic Trichoderma spp. isolated from healthy Coffea arabica roots are capable of controlling coffee tracheomycosis. Diversity 5, 750-766. https://doi.org/10.3390/d5040750 (2013).

95. Druzhinina, I. S. et al. An oligonucleotide barcode for species identification in Trichoderma and Hypocrea. Fungal Gen. Biol. 42, 813-828. https://doi.org/10.1016/j.fgb.2005.06.007 (2005).

96. Dodd, S. L., Lieckfeldt, E. \& Samuels, G. J. Hypocrea atroviridis sp. nov., the teleomorph of Trichoderma atroviride. Mycologia 95, 27-40. https://doi.org/10.2307/3761959 (2003).

97. Montoya, Q. V., Meirelles, L. A., Chaverri, P. \& Rodrigues, A. Unraveling Trichoderma species in the attine ant environment: Description of three new taxa. Antonie Van Leeuwenhoek 109, 633-651. https://doi.org/10.1007/s10482-016-0666-9 (2016).

98. Karlsson, M., Atanasova, L., Jensen, D. F. \& Zeilinger, S. Necrotrophic mycoparasites and their genomes. Microbiol. Spectrum 5, 1-21. https://doi.org/10.1128/microbiolspec.FUNK-0016-2016 (2017).

99. Kubicek, C. P. et al. Evolution and comparative genomics of the most common Trichoderma species. BMC Genomics 20, 485. https://doi.org/10.1186/s12864-019-5680-7 (2019).

100. Carrión, G. \& Rico-Gray, V. Mycoparasites on the coffee rust in Mexico. Fungal Divers. 11, 49-60 (2002).

101. James, T. Y., Marino, J. A., Perfecto, I. \& Vandermeer, J. Identification of putative coffee rust mycoparasites via single-molecule DNA sequencing of infected pustules. Appl. Environ. Microbiol. 82, 631-639. https://doi.org/10.1128/AEM.02639-15 (2016).

102. Oxfam International. Coffee rust fungus threatens employment collapse in Central America. www.oxfam.org (2014).

103. Ward, R., Gonthier, D. \& Nicholls, C. Ecological resilience to coffee rust: Varietal adaptations of coffee farmers in Copán, Honduras. Agroecol. Sustain. Food Syst. 41, 1081-1098. https://doi.org/10.1080/21683565.2017.1345033 (2017).

104. Keane, R. M. \& Crawley, M. J. Exotic plant invasions and the enemy release hypothesis. Trends Ecol. Evol. 17, 164-170. https:// doi.org/10.1016/S0169-5347(02)02499-0 (2002).

105. Hajek, A. E. \& Delalibera, I. Fungal pathogens as classical biological control agents against arthropods. Biol. Control 55, 13471358. https://doi.org/10.1007/978-90-481-3966-8_11 (2010).

106. Evans, H. C. Biological control of weeds with fungi. In The Mycota XI: Agricultural Applications 2nd edn (ed. Kempken, F.) 145-172 (Springer, Berlin, 2013).

107. Kepler, R. M. et al. A phylogenetically based nomenclature for Cordycipitaceae (Hypocreales). IMA Fungus 8, 335-353. https ://doi.org/10.5598/imafungus.2017.08.02.08 (2017).

108. Jackson, D., Skillman, J. \& Vandermeer, J. Indirect biological control of the coffee leaf rust, Hemileia vastatrix, by the entomogenous fungus Lecanicillium lecanii in a complex coffee agroecosystem. Biol. Control 61, 89-97. https://doi.org/10.1016/j.bioco ntrol.2012.01.004 (2012).

109. Evans, H. C. The endophyte-enemy release hypothesis: Implications for classical biological control. In Proceedings of the XII International Symposium on Biological Control of Weeds (eds Julien, M. H. et al.) 20-25 (CAB International, Wallingford, 2008).

110. McCook, S. Global rust belt: Hemileia vastatrix and the ecological integration of world coffee production since 1850. J. Global Hist. 1, 177-195. https://doi.org/10.1017/S174002280600012X (2006).

111. Poveda, J., Hermosa, R., Monte, E. \& Nicolás, C. The Trichoderma harzianum Kelch protein ThKEL1 plays a key role in root colonization and the induction of systemic defense in Brassicaceae plants. Front. Plant Sci. 10, 1478. https://doi.org/10.3389/ fpls.2019.01478 (2019)

112. Contreras-Cornejo, H. A., Macías-Rodríguez, L., Val, E. K. \& Larsen, J. The root endophytic fungus Trichoderma atroviride induces foliar herbivory resistance in maize plants. Appl. Soil Ecol. 124, 45-53. https://doi.org/10.1016/j.apsoil.2017.10.004 (2018).

113. Herrera-Rodríguez, M.C. Trichoderma spp. associated with coffee in Africa: taxonomy and potential uses for the biological control of coffee leaf rust and plant growth promotion. PhD Thesis, Universidade Federal de Viçosa, MG, Brazil (2019).

114. Hyde, K. D. \& Soytong, K. The fungal endophyte dilemma. Fungal Divers. 33, 163-173 (2008).

115. Gazis, R., Miadlikowska, J., Lutzoni, F., Arnold, A. E. \& Chaverri, P. Culture-based study of endophytes associated with rubber trees in Peru reveals a new class of Pezizomycotina: Xylonomycetes. Mol. Phylogenet. Evol. 65, 294-304. https://doi.org/10.1016/j. ympev.2012.06.019 (2012).

116. Gazis, R., Skaltas, D. \& Chaverri, P. Novel endophytic lineages of Tolypocladium provide new insights into the ecology and evolution of Cordyceps-like fungi. Mycologia 106, 1090-1105. https://doi.org/10.3852/13-346 (2014).

117. Rocha, A. C. S. et al. Foliar endophytic fungi from Hevea brasiliensis and their antagonism on Microcyclus ulei. Fungal Divers. 47, 75-84. https://doi.org/10.1007/s13225-010-0044-2 (2011).

118. Déon, M. et al. First characterization of endophytic Corynespora cassiicola isolates with variant cassiicolin genes recovered from rubber trees in Brazil. Fungal Divers. 54, 87-99. https://doi.org/10.1007/s13225-012-0169-6 (2012).

119. Martin, R., Gazis, R., Skaltsas, D., Chaverri, P. \& Hibbett, D. Unexpected diversity of basidiomycetous endophytes in sapwood and leaves of Hevea. Mycologia 107, 284-297. https://doi.org/10.3852/14-206 (2015).

120. Davis, A. P., Govaerts, R., Bridson, D. M. \& Stoffelen, P. An annotated taxonomic conspectus of the genus Coffea (Rubiaceae). Bot. J. Linn. Soc. 152, 465-512. https://doi.org/10.1111/j.1095-8339.2006.00584.x (2006).

121. Liu, Y. J., Whelen, S. \& Hall, B. D. Phylogenetic relationships among Ascomycetes: Evidence from an RNA Polymerse II Subunit. Mol. Biol. Evol. 16, 1799-1808. https://doi.org/10.1093/oxfordjournals.molbev.a026092 (1999).

122. Carbone, I. \& Kohn, L. M. A method for designing primer sets for speciation studies in filamentous Ascomycetes. Mycologia 91, 553-556. https://doi.org/10.2307/3761358 (1999).

123. Hepperle, D. SeqAssem danalysis and contig assembly of sequences. Sequentix-digitalDNA processing, Klein Raden, Germany. https://www.sequentix.de/software_seqassem.php (2004).

124. Tamura, K., Stecher, G., Peterson, D., Filipski, A. \& Kumar, S. Molecular evolutionary genetics analysis version 6.0. Mol. Biol. Evol. 30, 2725-2729. https://doi.org/10.1093/molbev/mst197 (2013).

125. Vaidya, G. D. J. \& Lohman, R. M. SequenceMatrix: concatenation software for the fast assembly of multigene datasets with character set and codon information. Cladistics 27, 171-180. https://doi.org/10.1111/j.1096-0031.2010.00329.x (2009).

126. Nylander, J. A. A. MrModeltest v2. Program Distributed by the Author (Uppsala University, Uppsala Evolutionary Biology, Centre, 2004).

127. Stamatakis, A. RAxML-VI-HPC: Maximum Likelihood-Based phylogenetic analyses with thousands of taxa and mixed models. Bioinformatics 22, 2688-2690. https://doi.org/10.1093/bioinformatics/btl446 (2006).

128. Miller, M. A., Pfeiffer, W. \& Schwartz, T. Creating the CIPRES Science Gateway for Inference of Large Phylogenetic Trees 1-8 (Gateway Computing Environments Workshop (GCE), New Orleans, 2010). https://doi.org/10.1109/GCE.2010.5676129.

129. Dettman, J. R., Jacobson, D. J., Turner, E. I., Pringle, A. \& Taylor, J. W. Reproductive isolation and phylogenetic divergence in Neurospora: Comparing methods of species recognition in a model eukaryote. Evolution 57, 2721-2741. https://doi. org/10.1111/j.0014-3820.2003.tb01515.x (2003).

130. Waller, J. M. et al. (eds) Plant Clinic Handbook (CAB International, Wallingford, 1998).

\section{Acknowledgements}

This work represents part of a research project submitted to the Departamento de Fitopatologia of the Universidade Federal de Viçosa, by M.C.H.R. as a requirement for a $\mathrm{PhD}$ in plant pathology. M.C.H.R. acknowledges 
financial support from the Coordenação de Aperfeiçoamento de Pessoal de Nível Superior (CAPES). This study was funded by World Coffee Research (WCR), CAPES and Conselho Nacional de Desenvolvimento Científico e Tecnológico $(\mathrm{CNPq})$ in Brazil. We thank the Institut de Recherche pour le Developpement (Cameroon) and the Ethiopian Institute of Agricultural Research (Ethiopia) for logistical support in Africa, and for arranging the necessary permits.

\section{Author contributions}

All authors contributed to the study conception and design. M.C.H.R., H.C.E. and R.W.B wrote the paper, with inputs from all authors, and carried out the experiments. D.M.M. undertook sample preparation. L.M.A. contributed to the interpretation of the results and data analysis. K.B.B. and M.K.N. facilitated and participated in material collection, isolations and analysis of specimens. All authors provided critical feedback and helped to shape the research.

\section{Competing interests}

The authors declare no competing interests.

\section{Additional information}

Supplementary Information The online version contains supplementary material available at https://doi. org/10.1038/s41598-021-84111-1.

Correspondence and requests for materials should be addressed to H.C.E. or R.W.B.

Reprints and permissions information is available at www.nature.com/reprints.

Publisher's note Springer Nature remains neutral with regard to jurisdictional claims in published maps and institutional affiliations.

(c) (i) Open Access This article is licensed under a Creative Commons Attribution 4.0 International License, which permits use, sharing, adaptation, distribution and reproduction in any medium or format, as long as you give appropriate credit to the original author(s) and the source, provide a link to the Creative Commons licence, and indicate if changes were made. The images or other third party material in this article are included in the article's Creative Commons licence, unless indicated otherwise in a credit line to the material. If material is not included in the article's Creative Commons licence and your intended use is not permitted by statutory regulation or exceeds the permitted use, you will need to obtain permission directly from the copyright holder. To view a copy of this licence, visit http://creativecommons.org/licenses/by/4.0/.

(C) The Author(s) 2021 